\title{
The Aryl Hydrocarbon Receptor as an Immune-Modulator of Atmospheric Particulate Matter-Mediated Autoimmunity
}

\author{
Chelsea A. O'Driscoll ${ }^{1,2}$ and Joshua D. Mezrich ${ }^{1 *}$ \\ ' Division of Transplantation, Department of Surgery, School of Medicine and Public Health, University of Wisconsin-Madison, \\ Madison, WI, United States, ${ }^{2}$ Molecular and Environmental Toxicology Center, School of Medicine and Public Health, \\ University of Wisconsin-Madison, Madison, WI, United States
}

OPEN ACCESS

Edited by:

Kenneth Michael Pollard, The Scripps Research Institute,

United States

Reviewed by:

David H. Sherr,

Boston University, United States

Laura Mandik-Nayak,

Lankenau Institute for Medical

Research, United States

${ }^{*}$ Correspondence:

Joshua D. Mezrich

mezrich@surgery.wisc.edu

Specialty section:

This article was submitted to Autoimmune and Autoinflammatory

Disorders,

a section of the journal

Frontiers in Immunology

Received: 02 October 2018 Accepted: 16 November 2018 Published: 06 December 2018

Citation: O'Driscoll CA and Mezrich JD (2018) The Aryl Hydrocarbon Receptor as an Immune-Modulator of Atmospheric

Particulate Matter-Mediated Autoimmunity.

Front. Immunol. 9:2833. doi: 10.3389/fimmu.2018.02833
This review examines the current literature on the effects of atmospheric particulate matter (PM) on autoimmune disease and proposes a new role for the aryl hydrocarbon receptor (AHR) as a modulator of $\mathrm{T}$ cells in PM-mediated autoimmune disease. There is a significant body of literature regarding the strong epidemiologic correlations between PM exposures and worsened autoimmune diseases. Genetic predispositions account for $30 \%$ of all autoimmune disease leaving environmental factors as major contributors. Increases in incidence and prevalence of autoimmune disease have occurred concurrently with an increase in air pollution. Currently, atmospheric PM is considered to be the greatest environmental health risk worldwide. Atmospheric PM is a complex heterogeneous mixture composed of diverse adsorbed organic compounds such as polycyclic aromatic hydrocarbons (PAHs) and dioxins, among others. Exposure to atmospheric PM has been shown to aggravate several autoimmune diseases. Despite strong correlations between exposure to atmospheric PM and worsened autoimmune disease, the mechanisms underlying aggravated disease are largely unknown. The AHR is a ligand activated transcription factor that responds to endogenous and exogenous ligands including toxicants present in PM, such as PAHs and dioxins. A few studies have investigated the effects of atmospheric PM on AHR activation and immune function and demonstrated that atmospheric PM can activate the AHR, change cytokine expression, and alter T cell differentiation. Several studies have found that the AHR modulates the balance between regulatory and effector $T$ cell functions and drives $T$ cell differentiation in vitro and in vivo using murine models of autoimmune disease. However, there are very few studies on the role of AHR in PM-mediated autoimmune disease. The AHR plays a critical role in the balance of effector and regulatory $T$ cells and in autoimmune disease. With increased incidence and prevalence of autoimmune disease occurring concurrently with increases in air pollution, potential mechanisms that drive inflammatory and exacerbated disease need to be elucidated. This review focuses on the AHR as a potential mechanistic target for modulating $T$ cell responses associated with PM-mediated autoimmune disease providing the most up-to-date literature on the role of AHR in autoreactive T cell function and autoimmune disease.

Keywords: atmospheric particulate matter, $\mathrm{T}$ cells, autoimmune disease, autoimmunity, aryl hydrocarbon receptor, polycyclic aromatic hydrocarbons 


\section{BACKGROUND}

Currently, there are over 80 recognized autoimmune diseases (1). In the United States alone, autoimmune diseases are among the most prevalent diseases effecting 24.5 million people or approximately $8 \%$ of the population $(1,2)$. Both incidence and prevalence of autoimmune diseases have been increasing worldwide (3-5), however the reasons for these increases remain unknown (4). Autoimmune disease results from failure of cells and tissues to distinguish self from non-self leading to a loss of self-tolerance and autoimmune pathology. Autoreactive T cells play a critical role in development of autoimmune diseases such as type 1 diabetes (T1D), rheumatoid arthritis (RA), multiple sclerosis (MS), and systemic lupus erythematosus (SLE) (610). Genetic predispositions account for approximately $30 \%$ of autoimmune diseases, leaving environmental factors as a major contributor $(11,12)$. While genetic predispositions play a role in disease incidence (13), epidemiologic studies strongly support that high levels of air pollution, specifically, particulate matter (PM) in the atmosphere, increase the incidence and severity of autoimmune disease $(1,3)$.

$\mathrm{PM}$, a component of air pollution, has emerged as the largest environmental risk factor for mortality worldwide (14). While many people equate exposure to inhaled PM with airway disease, its role in other systemic illnesses has also been well documented. Increases in incidence of autoimmune disease have occurred concurrently with increases in global air pollution $(3,4,14,15)$. Exposure to PM has been associated with aggravation of several autoimmune diseases including T1D, MS, RA, and SLE (16-32). Epidemiologic studies strongly suggest that exposure to PM can increase both incidence and severity of autoimmune diseases $(33,34)$.

Atmospheric PM is a complex mixture of solid particles and liquid droplets formed from a combination of primary sources, such as road transportation (diesel exhaust PM), stationary combustion (mainly domestic coal burning) and industrial processes (35), that emit PM directly into the atmosphere and secondary sources, such as gaseous vegetative emissions, motor vehicle emissions, and wood-smoke emissions (36), that emit gaseous PM precursors into the atmosphere and undergo oxidation reactions to form $\mathrm{PM}(35,36)$. The diverse primary emission sources and secondary chemical reactions that lead to atmospheric PM components result in complex mixtures of PM components that include metals, nitrates, sulfates, and diverse organic compounds like polycyclic aromatic hydrocarbons (PAHs) $(37,38)$.

PM contains organic compounds such as PAHs and dioxins, among others, which are aryl hydrocarbon receptor (AHR) ligands, adsorbed to its surface (37-40). The AHR is ligandactivated transcription factor that responds to exogenous ligands, as well as endogenous ligands, and upregulates cytochrome P450 (CYP) metabolizing enzymes as well as other gene targets (40). The majority of high affinity AHR ligands are synthetic in nature and include 2,3,7,8-tetrachlorodibenzo-p-dioxin (TCDD), the prototypic AHR ligand, and PAHs, among others $(41,42)$. The most potent AHR ligands are more metabolically stable, like TCDD and dioxin-like compounds, whereas less potent ligands, like PAHs, are more metabolically labile (41). Early studies of the AHR focused on understanding the underlying mechanisms of TCDD toxicity. It was discovered that TCDD exposure caused severe toxicity and life-threatening manifestations such as progressive liver failure, emphysema, renal failure, and myocardial degeneration, among other pathologies (43). In addition to these manifestations, rodent studies described immune phenotypes of TCDD exposure revealing a role of AHR in the immune system. Following TCDD exposure, rodents suffered profound effects on the developing immune system as well as dose-dependent thymic involution, depletion of other lymphoid organs, and reduced circulating lymphocyte counts (43). The discovery of immune pathologies associated with TCDD exposure led immunologists to focus on the AHR.

The AHR has been studied in many aspects of immunology, but a major focus has been on regulatory and effector $\mathrm{T}$ cell differentiation and function. Ahr is expressed in most $\mathrm{CD}_{4}^{+}$ $\mathrm{T}$ cell subsets, with highest expression in $\mathrm{T}$ helper (Th)17, type 1 regulatory $\mathrm{T}$ cells $(\mathrm{Tr} 1)$, forkhead box $\mathrm{P} 3(\mathrm{FOXP} 3)^{+}$ regulatory T cells (Treg), followed by Th1 and Th2 $(44,45)$ and is critical in modulating the balance between Th17 and Treg cells $(44,46)$. TCDD has been associated with an increase in Treg cells and immunosuppression, whereas other ligands such as 6formylindolo[3,2-b] carbazole (FICZ), a tryptophan breakdown product, has been associated with enhanced Th17 effector cells and inflammation $(44,46)$. In the context of autoimmune disease, TCDD has been shown to enhance Treg differentiation and suppress experimental autoimmune encephalomyelitis (EAE), a murine model of autoimmune disease, and FICZ has been shown to enhance Th17 differentiation and worsen $\operatorname{EAE}(44,46)$.

This review summarizes the current research regarding the role of PM on development and/or progression of autoimmune disease. We first provide a brief overview of the role autoreactive $\mathrm{T}$ cells play in autoimmune diseases and summarize the evidence that PM impacts T cells and autoimmune disease. Given the numerous and extensive reviews on AHR ligands (40,47), we only highlight PM-mediated AHR effects in vitro and in vivo. We then focus on the AHR as the receptor central to the mechanism behind modulating $\mathrm{T}$ cell responses in PM-mediated autoimmune disease. We chose to focus on four diseases, T1D, RA, MS, and SLE as strong correlations between PM exposure and worsened disease have been observed and the AHR has been linked to these diseases as well. We examine the data demonstrating the effects of organic constituents adhered to PM, specifically AHR ligands, on T cells and suggest the AHR pathway as a target for modulating PM-mediated autoimmune disease. We propose a novel hypothesis that AHR ligands present in atmospheric PM activate the AHR shifting the T cell balance from regulatory to effector ultimately leading to PM-mediated autoimmune disease.

\section{THE ROLE OF AUTOREACTIVE T CELLS IN AUTOIMMUNE DISEASE}

In an attempt to develop a rigorous immune system that can react quickly and decisively to outside insults and internal threats 
(including bacteria, viruses, and dysfunctional/dysregulated cells), but at the same time to avoid autoimmune insults, multiple non-redundant checkpoints have evolved during the development of immune cells to delete self-reactive lymphocytes and generate self-tolerance (4). Central tolerance eliminates selfreactive $\mathrm{T}$ cells during their development by negative selection, however, this process is leaky and some self-reactive lymphocytes escape to the periphery $(4,48)$. Mechanisms of peripheral tolerance control these autoreactive $\mathrm{T}$ cells to avoid damage to cells and tissues through employment of anergy, immunological ignorance, and/or regulation (4). Suppression of autoreactive $\mathrm{T}$ cells by Tregs is one critical pathway in the induction of peripheral tolerance (4). Regulatory $\mathrm{T}$ cells suppress the actions of effector $\mathrm{T}$ cells and control the immune response through cell contact, secretion of inhibitor cytokines, and competition for growth factors $(4,49,50)$. Tregs can become overwhelmed by persistent inflammation during an immune response or in some cases are dysfunctional resulting in unregulated effector responses and ultimately autoimmune disease (4, 49, 5153). The complex development of lymphocytes and random rearrangement of adaptive lymphocyte receptors allows for immense diversity of antigen receptor specificity but comes at the cost of creating self-reactive $\mathrm{T}$ lymphocytes that escape to the periphery and evade or overcome peripheral tolerance mechanisms ultimately leading to autoimmune disease (54).

Autoreactive $\mathrm{T}$ cells play a role in the pathology of autoimmune disease by overcoming central and peripheral tolerance and rendering Tregs insufficient to dampen inflammatory responses. Genetic predispositions account for less than half of all autoimmune disease leaving environmental factors like PM as a potential contributor to the development of autoreactive T cells. Our studies focus on identifying the active component of PM that exacerbates autoimmune disease and elucidating the mechanism through which it acts. Currently, the focus is on understanding how PAHs present in PM act through the AHR to shift the $\mathrm{T}$ cell balance and alter autoimmune disease states.

\section{PARTICULATE MATTER}

\section{Defining PM}

PM is a complex mixture of solid particles and liquid droplets that vary in physical and chemical properties as well chemical composition and origin, over time and space $(35,55)$. PM is defined based on size, specifically aerodynamic equivalent diameter (AED) (56). AED is a measure of behavior of the particle in the air and is a function of particle diameter, density, shape, and surface characteristics (57). The particles are further subdivided into AED fractions based on how the particles are generated and their ability to penetrate and deposit in human airways: $\mathrm{PM}_{10}(<10 \mu \mathrm{M}), \mathrm{PM}_{2.5}(<2.5 \mu \mathrm{M}), \mathrm{PM}_{0.1}(<0.1 \mu \mathrm{M})$ (56). It is important to appreciate that $\mathrm{PM}_{10}$ contains, ultrafine $\mathrm{PM}_{0.1}$, fine $\mathrm{PM}_{0.1-2.5}$, and coarse $\mathrm{PM}_{2.5-10}$ fractions (56). By far, the greatest number of particles fall into the ultrafine size range, $\mathrm{PM}$ with an AED of $0.1 \mu \mathrm{M}$ or less $\left(\mathrm{PM}_{0.1}\right)$ (35). The total number and the total surface area of these particles increases exponentially as the diameter of the particle deceases, and as the diameter of the particle decreases, the total particle mass exponentially decreases (56). $\mathrm{PM}_{0.1}$ ultrafine particles are inherently unstable in the atmosphere and coagulate and condensate to form larger particles (35). $\mathrm{PM}_{2.5}$ fine particles also grow by coagulation and condensation in the atmosphere (35). $\mathrm{PM}_{10}$ coarse particles vary in size and while they contribute little to particle number, they contribute majorly to particle mass (35).

\section{Composition and Sources of PM}

Atmospheric PM is a complex mixture of solid particles and liquid droplets formed from a combination of primary sources that emit PM directly into the atmosphere and secondary sources that emit gaseous PM precursors into the atmosphere and undergo oxidation to form PM $(35,36)$. These complex mixtures of PM components include metals, nitrates, sulfates and diverse organic compounds like PAHs $(37,38)$. Anthropogenic primary sources include road transportation (diesel exhaust particulate matter), stationary combustion (mainly domestic coal burning) and industrial processes (35). The nature of the industrial particles depends on the process; however combustion particles are generally dominated by black or elemental carbon and heavy organic materials such as PAHs (58). Secondary sources emit PM precursors, which are gases that lead to PM formation through atmospheric reactions and include gaseous vegetative emissions, motor vehicle emissions, and wood-smoke emissions (36).

\section{Particulate Matter-Mediated Autoimmune Disease}

Increases in global air pollution have occurred concurrently with a dramatic increase in autoimmune incidence $(3,4,14,15)$. Exposure to air pollution, specifically PM, is associated with aggravation of various autoimmune diseases including T1D, RA, MS, and SLE (16-32). Epidemiologic studies strongly suggest that exposure to PM can increase both incidence and severity of autoimmune disease $(33,34)$.

\section{PM and Autoreactive T Cells}

Exposure to PM has been associated with aggravation of autoimmune diseases including T1D, RA, MS, and SLE, which will be the focus of this review (16-32). Pathology of autoimmune diseases can be mediated by autoreactive $\mathrm{T}$ cells and exposure to PM has been shown to alter effector $\mathrm{T}$ cell populations in healthy $\mathrm{T}$ cells as well as diseased. In human $\mathrm{T}$ cells from healthy donors, diesel exhaust particles (DEPs) from low emission diesel engines decreased expression of CD25, a marker for $\mathrm{FOXP}^{+}$Tregs, on $\mathrm{CD}^{+} \mathrm{T}$ cells and induced autophagic-lysosomal blockade in vitro which has been associated with pathogenic events of autoimmune disease (59). Using cells from atopy-prone mice, which are highly sensitive hosts, Nakamura et al. (60) showed that nanoparticle-rich DEP reduced cell viability and proliferation in a dose-related manner. Retinoic-acid receptor-related orphan receptor gamma $\mathrm{t}(\mathrm{ROR} \gamma \mathrm{t})$ expression and subsequent IL-17A production/release by the cells was increased in the splenocytes in a dose-dependent manner implicating Th17 cells in PMmediated immune responses. Additionally, $\mathrm{CD} 4^{+}$and $\mathrm{CD} 8^{+} \mathrm{T}$ cells exposed to $\mathrm{PM}_{2.5}$ significantly elevated mRNA and protein 
levels of inflammatory cytokine production in a macrophagedependent manner (61). Furthermore, in a model of chronically inhaled $\mathrm{PM}_{2.5}$ for 24-28 weeks, exposure to $\mathrm{PM}_{2.5}$ resulted in increased $\mathrm{T}$ cell infiltration and increased activation of effector $\mathrm{T}$ cells in the lungs and indicates that $\mathrm{PM}_{2.5}$ potentiates a proinflammatory Th1 response (62). In addition, van Voorhis et al. (63) demonstrated that a 3 day intranasal instillation of a standard reference material (SRM)1649b, an ambient urban dust PM sample, significantly upregulated IL-17 mRNA in the lung of C57BL/6 mice. Moreover, in a mixed leukocyte culture, using C57BL/6 splenocytes activated with Balb/c DCs, which creates an immune response, a significant increase in IL-17 protein was measured as well as IL-22 mRNA suggesting an increase in Th17 responses (63). Likewise, Castaneda et al. (64) demonstrated that PM enhances DC activation and primes naïve $\mathrm{T}$ cell differentiation toward a Th17-like phenotype in vitro and in vivo.

\section{PM and T1D}

T1D is an autoimmune disease resulting in targeting of islet cell autoantigens leading to a severe loss of pancreatic $\beta$ cells $(9,65)$. T1D patients exhibit defects in peripheral tolerance including effector resistance to Treg suppression (66) and/or impaired Treg function (67). Incidence of T1D has been increasing by 2$5 \%$ worldwide (68) especially in children $0-4$ years of age (69) and prevalence is approximately 1 in 300 in the U.S. by age 18 (68). Long-term exposure to $\mathrm{PM}_{2.5}$ at low levels has been related to increased mortality attributable to T1D (17). Hathout et al. (20) found pre-diagnosis $\mathrm{PM}_{10}$ exposure was significantly higher in children diagnosed before 5 years of age compared to healthy controls. Likewise, a study from Chile found that $\mathrm{PM}_{2.5}$ levels were associated with the onset of T1D in children (19). Beyerlein et al. (16) analyzed data from a populationbased register monitoring incidence of diabetes in children and youths in Germany since 2009 and found that high exposure to the traffic-related air pollutants $\mathrm{PM}_{10}, \mathrm{NO}_{2}$, and possibly $\mathrm{PM}_{2.5}$ accelerated the manifestation of T1D, but only in very young children. Additionally, children of mothers exposed to high levels of air pollution while pregnant had a higher risk of later developing T1D (21). Di Ciaula et al. (18) showed T1D incidence rate was significantly and positively correlated with mean yearly $\mathrm{PM}_{10}$ in Italy, however the correlation between T1D and $\mathrm{PM}_{10}$ air levels was more evident in children 10-14 years and 5-9 years than $0-4$ years. Together, these data demonstrate an association between exposure to PM and diagnosis and exacerbation of T1D in children, mainly under the age of 5 . On the other hand, a study in Southern California, demonstrated that pre-diagnosis $\mathrm{PM}_{10}$ exposure in children was not associated with increased odds of T1D (70). In adult disease, Michalska et al. (71) showed a relationship between the number of new T1D cases and mean annual concentration of $\mathrm{PM}_{10}$ in 2016, but not 2015 in Poland. Additionally, Yitshak et al. (72) showed that the 3-month average concentration of $\mathrm{PM}_{10}$ was associated with increases of serum glucose, HbAlc (average glucose concentration over 3 months and a marker for diabetic complications), low-density lipoprotein and triglycerides, and decrease of high-density lipoprotein with strongest associations observed among subjects with diabetes.
Conversely, Lanzinger et al. (73) found no relationship between $\mathrm{PM}$ and T1D and no significant associations between $\mathrm{HbAlc}$ and $\mathrm{PM}_{10}$. Overall, these data suggest exposure to PM may increase incidence, onset, and accelerate T1D in children and may be associated with worsened diabetes in adults.

\section{PM and RA}

RA is characterized by accumulation of inflammatory cells in the joints, leading to synovitis and severe tissue damage $(74,75)$. RA is a systemic autoimmune disease effecting approximately $1 \%$ of the adult population (76) and overall heritability of RA is estimated to be approximately $60 \%$ (77), leaving environmental pollutants, such as PM, as significant factors. Chang et al. (27) detected an increased risk of RA in participants exposed to $\mathrm{PM}_{2.5}$ and there are several studies, including the Nurses' Health Study (76), that show an elevated risk of RA in people living less than or equal to 50 meters of major highways $(76,78)$. However, in the same population of nurses, adult exposures to specific air pollutants were not associated with an increased RA risk (79). Similarly, in the Swedish Epidemiological Investigation of Rheumatoid Arthritis, no evidence of an increased risk of $\mathrm{RA}$ with exposure to traffic pollutants, including $\mathrm{PM}_{10}$ was measured (80). Nonetheless, there are multiple studies that show an increased incidence of RA in urban areas compared to rural areas $(81,82)$ and living near air pollution emitters was associated with higher risks of developing RA and of producing RA-specific autoantibodies (82). Additionally, Gan et al. (83) showed that PM exposure was not associated with RA-related autoantibodies and joint signs among individuals without RA, but at an increased risk of developing RA.

Moreover, in children, case control studies indicated an increased relative risk for juvenile idiopathic arthritis (JIA), also known as juvenile rheumatoid arthritis, in American children $<5.5$ years of age was found with increasing $\mathrm{PM}_{2.5}$ exposure, but evidence was less clear for links between exposure to air pollutants and development of RA (84). Furthermore, Zeft et al. (85) demonstrated that increased concentrations of $\mathrm{PM}_{2.5}$ in the preceding 14 days of diagnosis were associated with significantly elevated risk of JIA onset in preschool aged children but not older children. Additionally, Zeft et al. (86) showed the most positive associations of short-term $\mathrm{PM}_{2.5}$ exposure with systemic JIA were in children younger than 5.5 years. Together these data suggest a strong relationship between exposure to PM and risk of developing RA in both adults and children, however the link between PM exposure and exacerbation of RA is less clear. Overall, these data suggest a potential role of PM exposure in development and/or exacerbation of juvenile and adult onset RA.

\section{PM and MS}

MS is a demyelinating inflammatory disorder of the central nervous system (CNS) mediated by pathogenic $\mathrm{T}$ cells against myelin antigens (87). Like other autoimmune diseases, MS has a multifactorial etiology and likely results from an interaction between genetic predispositions, like mutations in the class II major histocompatibility genomic region, as well as environmental factors, like $\mathrm{PM}_{10}$ and $\mathrm{PM}_{2.5}$. A strong link between risk of MS relapse or hospitalization and concentrations 
of $\mathrm{PM}_{10}$ has been established world-wide $(22,24-26,88,89)$. Additionally, Gregory II et al. (23) found strong associations between total MS prevalence rates as well as individual female and male prevalence rates with mobile sources of $\mathrm{PM}_{2.5}$ and $\mathrm{PM}_{10}$. Moreover, a significant spatial correlation between the clustering of MS cases and patterns of $\mathrm{PM}_{10}$ was found in Tehran, Iran in that significantly higher yearly averages of $\mathrm{PM}_{10}$ existed in regions where MS patients lived compared to healthy controls (90). In pediatric MS, poor air quality was related to increased odds of developing MS in the pediatric population (91). For those pediatric patients living less than 20 miles from a recruitment center, the odds for MS increased by 4 as the air quality worsened and similarly, for those living more than 20 miles from the recruitment centers, the odds for MS doubled as air quality worsened (91). To understand how PM may be aggravating MS, Bergamaschi et al. (92) investigated the relationship between $\mathrm{PM}_{10}$ levels and inflammatory lesions in the brains of patients with MS using MRI data with gadolinium (Gd), which marks blood brain barrier breakdown and inflammatory lesions, in Italy. They found that $\mathrm{PM}_{10}$ levels in the $5,10,15,20$, and 25 days before brain MRIs were higher with reference to MRIs of patients with $\mathrm{Gd}$ enhanced lesions $(\mathrm{Gd}+)$ vs. patients with MRIs having no Gd enhanced lesions (Gd-) and there was a significant association between $\mathrm{Gd}+\mathrm{MRI}$ and $\mathrm{PM}_{10}$ levels. This suggests that PM exposure may be linked to increased inflammatory lesions and blood brain barrier leakiness and breakdown associated with MS. Furthermore, Klocke et al. (93, 94) exposed pregnant mice to PM and characterized endpoints after birth. Gestational exposure to concentrated ambient fine and ultrafine particles at levels consistent with environmental levels near California freeways altered neuropathology (93). These data suggest that gestational PM exposure alters the developing brain.

Contrarily, using the Nurses' Health Study, there was no relationship found between PM exposure and MS risk for women in the U.S (95). Similarly, Chen et al. (96) found no association between living near a major roadway in MS in patients in Ontario, Canada in a population-based cohort study. In Madrid, Spain no associated was found between $\mathrm{PM}_{10}$ or $\mathrm{PM}_{2.5}$ and MS emergency room admissions across the period analyzed (97). Despite these studies that did not find an associated between PM and MS risk or exacerbation, a large body of evidence exists suggesting that PM contributes to both onset and exacerbation. Cumulatively, these data demonstrate a potential role of PM exposure in the development and exacerbation of MS, however the specific mechanisms remain unknown.

\section{PM and SLE}

SLE is a caused by an aberrant autoimmune response to unknown autoantigens by both autoreactive $\mathrm{T}$ cells and autoantibodies that effect vital organs such as brain and kidney (98). PM exposure has been linked to SLE in both adult and pediatric patients (28-32, 99). In adults, Bernatsky et al. (29) showed that antibodies against double-stranded DNA (anti-dsDNA) and urinary casts, markers of disease related to SLE, were significantly associated with $\mathrm{PM}_{2.5}$ levels averaged over 24 or $48 \mathrm{~h}$ before clinical visits in Montreal, Canada. Moreover, Bernatsky et al. (30) also demonstrated the odds of having a systemic autoimmune rheumatic disease (SARD), which includes SLE, increased with $\mathrm{PM}_{2.5}$ levels (30). Additionally, in two different Canadian provinces, Alberta and Quebec, the odds of being diagnosed with SARDs increased with $\mathrm{PM}_{2.5}$ levels (31). Similarly, Fernandes et al. (32) observed a significant increased risk of juvenile-onset SLE disease activity 13 and 16 days after exposure to $\mathrm{PM}_{10}$. On days where PM levels exceeded the World Health Organization (WHO) air quality standard $\left(50 \mathrm{mg} / \mathrm{m}^{3}\right)$, the risk of juvenile-onset SLE activity was $79.0 \%$ higher than it was on days with levels below the standard (32). Together these data suggest a potential role of PM in the development and exacerbation of SLE.

\section{Summary}

Several studies from around the world demonstrate an association between the risk of development and/or exacerbation of autoimmune diseases and exposure to PM, and a few do not (Table 1). While the epidemiological data is strong, the mechanistic understanding of how PM increases the risk of developing autoimmune disease or exacerbates autoimmune disease remains largely unknown. The lack of mechanistic understanding of the components of PM responsible for the epidemiologic correlations as well as the pathways in which the components act, make understanding the contradictory data difficult. Despite the contradictory data, several studies establish clear correlations between exposure to PM and autoimmune diseases. Based on the data presented, one possible mechanism is that PM exposure increases inflammation and exacerbates autoimmune disease, however the specific pathways and mechanisms that are targeted to cause the inflammatory responses are unclear. Identifying components of PM and specific pathways associated with PM-mediated autoimmune disease will allow for targeted therapies to delay onset and ameliorate symptoms caused by PM exposure.

\section{The Relationship Between PM and the AHR}

Epidemiologic data provides strong associations between PM and autoimmune diseases, however the mechanisms in which PM elicits its negative health impacts are largely unknown. PM contains AHR ligands such as PAHs, dioxins, and polychlorinated biphenyl (PCBs) congeners, among others adsorbed to its surface. Andrysik et al. (120) found that the organic extract of SRM1649a, ambient urban dust PM containing dioxins, PCBs, and PAHs, which are present at the highest concentration of AHR ligands adhered to the sample, as well as its neutral and polar fractions, were potent inducers of AHRmediated responses. These responses occurred at doses one order of magnitude lower than DNA damage and included induction of AHR-mediated transcription of CYP1A1 and CYP1B1 and AHRdependent cell proliferation (120). PAHs were major contributors to overall AHR-mediated activity (120). Additionally, extracts of real-world $\mathrm{PM}_{10}$ samples obtained from southwest United States and Mexico were rich in PAHs and had significant activity in an ethoxyresorufin-O-deethylase (EROD) which measures CYP1A1 induction, and in a luciferase assay, which measures AHR activation (121). 
TABLE 1 | Summary of the effects of PM and AHR agonists on autoimmunity.

\begin{tabular}{|c|c|c|c|c|c|}
\hline & & Treatment & Immunosuppressive & Immunostimulatory & No effect on autoimmunity \\
\hline \multirow[t]{10}{*}{ Pre-clinical } & PM & DEP PM & & $(100)$ & \\
\hline & & DEP OF & $(100)$ & $(100)$ & \\
\hline & & Ambient PM & $(101)$ & $(63,64)$ & \\
\hline & & Ambient OF & & & \\
\hline & AHR agonists & TCDD & $(46,102,103)$ & $(104-106)$ & \\
\hline & & Norisoboldine & $(109)$ & & \\
\hline & & Tetrandrine & $(110)$ & & \\
\hline & & Sinomenine & $(111)$ & & \\
\hline & & Laquinimod & $(112)$ & & \\
\hline & & ITE & (113) & & \\
\hline \multirow[t]{2}{*}{ Clinical } & PM & & & $\begin{array}{l}(16,18-21,23,27,59,71,72,76 \\
78,81-86,90,92)\end{array}$ & $(70,71,73,79,80,83,85,95-97)$ \\
\hline & AHR antagonists & GNF351 & $(118,119)$ & & \\
\hline
\end{tabular}

Similarly, when looking at immune cells, den Hartigh et al. (122) examined the effects of PM collected from Fresno, California on activation of human monocytes and found that PM exposure increased CYP1A1 expression, and inhibition of the AHR reduced the CYP1A1 levels and inflammatory responses. Likewise, Jaguin et al. (123) showed that AHR and nuclear factor erythroid 2-related factor $2(\mathrm{Nrf} 2)$ pathways were activated in human macrophages after DEP exposure. Specifically, AHR activation by DEP lowered the capacity of human macrophages to secrete inflammatory cytokines, IL-6 and IL-12p40 (123). van Voorhis et al. (63) demonstrated that a 3 day intranasal instillation of SRM1649b not only increased IL-17mRNA in the lung, but also significantly increased CYP1A1 mRNA in vivo. In addition, in a mixed leukocyte culture, where splenocytes from C57BL/6 mice are stimulated with $\mathrm{DCs}$ from Balb/c mice to generate an immune response, a significant increase in IL-17 protein levels were observed as well as an increase in CYP1A1 mRNA (63).

When examining the effects of intact PM vs. organic extracts, bioavailability of active components, such as PAHs, has been shown to alter biologic responses. PM samples from complete combustion provided a stronger response in the PAH-CALUX assay, which measures PAH-induced AHR activity, and PM from incomplete combustion provided a weaker response suggesting that PM contains organic components that strongly adsorb PAHs thereby reducing their bioavailability (124). These findings were found to be strongly associated with the amount of elemental carbon present in the PM samples with higher elemental carbon favoring less bioavailability of PAHs in PM (124).
Additionally, Libalova et al. (125) demonstrated that exposure to extractable organic matter (EOM) induced significantly lower DNA adduct levels, while expression of AHR-dependent PAHactivating enzymes as well as other AHR target genes, was strongly enhanced compared to benzo[a]pyrene-treated cells. This suggests that the genotoxicity of benzo[a]pyrene is inhibited by other organic compounds bound to $\mathrm{PM}_{2.5}$ but induction of AHR-dependent gene expression by benzo[a]pyrene is not inhibited by EOM constituents (125). Vondracek et al. (126) found that although PAHs are major contributors to the AHRmediated activity of organic compounds associated with particles derived from diesel exhaust, polar compounds, which does include polar PAH derivatives generated through metabolism, present in these mixtures are more active in human cells, as compared with rodent cells. Misaki et al. (127) further demonstrated that polar fractions of DEP contribute significantly to AHR activation in vitro. Likewise, Palkova et al. (128) found that PAHs, as well as polar compounds contained within DEP, are important inducers of the AHR-mediated activity and contributed significantly to formation of stable DNA adducts, activation of DNA damage response signaling pathways, and induction of cell death. Together, these data suggest the AHR has the potential to be a modulator of PM-mediated disease.

In the context of exposure to PM and its derivatives, O'Driscoll et al. (100) demonstrated that exposure to standard reference material (SRM)1650b PM, which is from a 4cylinder diesel truck engine, enhanced Th17 differentiation in an AHR-dependent manner and SRM2975, which is from a 2-cylinder diesel forklift engine, enhanced Th1 differentiation 
in an AHR-dependent manner [Figure 1 from O'Driscoll et al. (100)]. In addition, the chemically-extracted OF of SRM1650b and SRM2975 which contains AHR ligands, such as PAHs, enhanced Th17 differentiation in an AHR-dependent manner (100). Synthetic PAH mixtures which include 15 PAHs present in SRM1650b and SRM2975 enhanced Th17 differentiation, however SRM1650b synthetic PAH mixture required the AHR at high doses and at lower doses enhanced Th17 differentiation only in the absence of CYP enzymes (100). SRM2975 synthetic PAH mixture enhanced Th17 differentiation only in the absence of CYP enzymes suggesting that the inhibition of CYP enzymes prevents the breakdown of the active component allowing for the observed T cell effect [(Figure 1 from O'Driscoll et al. (100)] (100). Similarly, O'Driscoll et al. (101) demonstrated that an ambient urban dust PM sample enhanced Th17 differentiation in an AHR-dependent manner. Likewise, Castaneda et al. (64) showed that PM enhanced DC activation and primed naïve $\mathrm{T}$ cells toward a Th17-like phenotype in an AHR-dependent manner in vitro and in vivo.

\section{Aryl Hydrocarbon Receptor: an Environmental Sensor}

The AHR is a member of the PER-ARNT-SIM (PAS) superfamily $(129,130)$ and is a ligand-activated transcription factor that in the absence of ligand is maintained as an inactive complex in the cytosol with two molecules of the chaperone heat shock protein (HSP) 90 (131, 132), as well as aryl hydrocarbon associated protein 9 (ARA9) (also known AIP1 or XAP2) $(133,134)$ and p23 (135). Together, these chaperones contribute to the cytosolic localization of unliganded AHR, protect it from degradation, and maintain a favorable state for ligand and DNA-binding (136-138). Upon ligand binding, the AHR-complex undergoes a conformational change that reveals its nuclear localization sequence (139). As a result of this conformational change, AHR sheds its cellular chaperones $(140,141)$, translocate to the nucleus, where it heterodimerizes with another bHLHPAS protein, aryl hydrocarbon nuclear translocator (ARNT) (also known as HIF1 $\beta$ ) (142). The ligand-activated AHR-ARNT complex is capable of binding to specific sequences of DNA (TNGCGTGT-) known as aryl hydrocarbon response elements (AHREs) [also known as dioxin response elements (DREs) or xenobiotic response elements (XREs)] (143-145) and inducing transcription of target loci such as CYP1A1 (Figure 2) (146, 147). The AHR is a promiscuous receptor that it binds both exogenous ligands, such as TCDD and PAHs, and endogenous ligands, such as FICZ and 2-( $1^{\prime} \mathrm{H}$-indole-3'-carbonyl)-thiazole4-carboxylic acid methyl ester (ITE), that are structurally diverse $(40,47,148)$.

The AHR is subject to negative regulation. Following ligandinduced activation and nuclear export (141), the AHR is degraded via a $26 \mathrm{~S}$ proteasome pathway (149-151). Another mechanism in which the AHR is negatively regulated is by the upregulation of the aryl hydrocarbon receptor repressor (AHRR), a bHLH-PAS protein that functions as a transcriptional

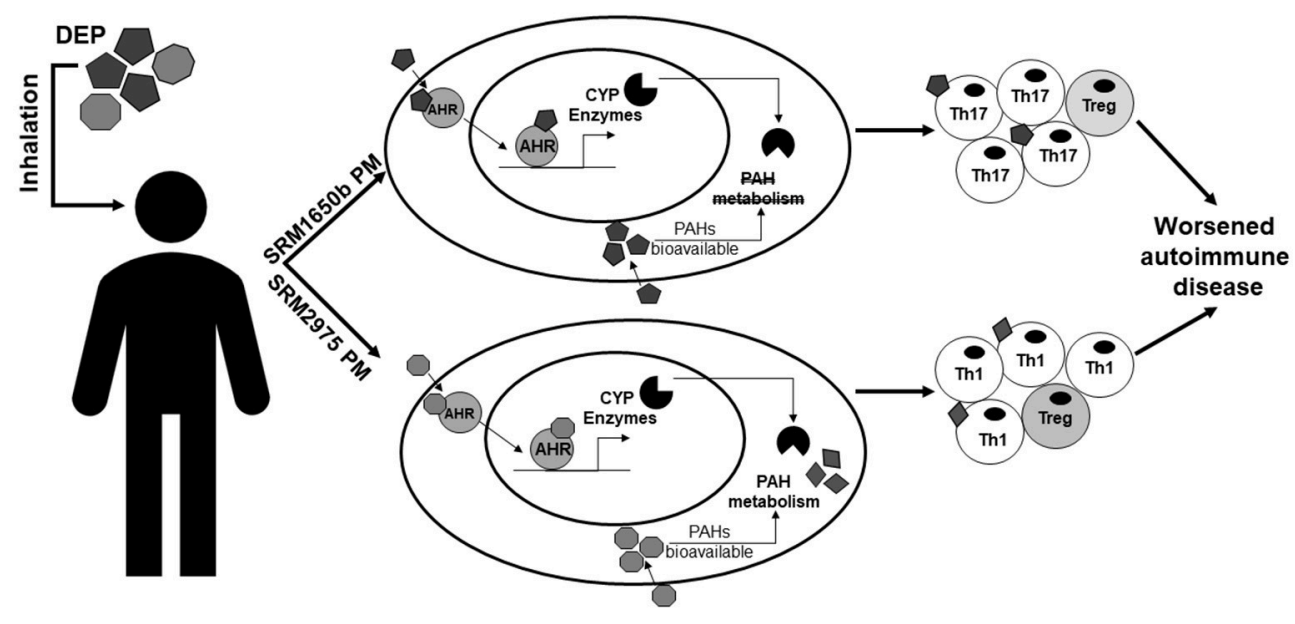

FIGURE 1 | Summary of the effects of DEP on T cells and autoimmune disease. This figure from O'Driscoll et al. (100) summarizes the differential effects of two DEPS, SRM1650b from a 4-cylinder diesel engine, and SRM2975 from a 2-cylinder diesel engine on T cell differentiation and autoimmune disease. SRM1650b enters the T cell, binds AHR, which then translocates to the nucleus and binds DNA, driving transcription of CYP enzymes (top). SRM1650b enhances Th17 differentiation in an AHR-dependent manner and worsens autoimmune disease (top). Based on the in vivo EAE data using the intact PM and chemically-extracted OF, SRM1650b requires the particle to aggravate autoimmune disease because of bioavailability of the PAHs and their ability to activate the AHR. Like SRM1650b, SRM2975 enters the T cell, binds AHR, translocates to the nucleus, binds DNA, and drives transcription of CYP enzymes (bottom). However, SRM2975 enhances Th1 differentiation in an AHR-dependent manner but still worsens autoimmune disease (bottom). Based on the in vivo EAE data demonstrating SRM2975 worsens autoimmune disease in PM and OF forms and the in vitro data showing a role of CYP enzymes in T cell differentiation, metabolism of SRM2975 plays a role in its ability to worsen autoimmune disease in that CYP metabolism of PAHs may lead to more potent intermediates that drive immune responses in vivo. Additionally, in the presence of PAHs and AHR activation, enhanced effector differentiation by both samples results in increase in Th17 or Th1 cells and a reduction in Treg cells. However, when PAHs are at much lower concentrations as with the low doses, enhanced effector differentiation is lost and Treg differentiation is enhanced. SRM, standard reference materials; DEPs, diesel exhaust particles; AHR, aryl hydrocarbon receptor; CYP, cytochrome P450; PAH, polycyclic aromatic hydrocarbons. This figure or a version of this figure was published in Particle and Fibre and Toxicology and is licensed under the Creative Commons Attribution 4.0 International Public License. 


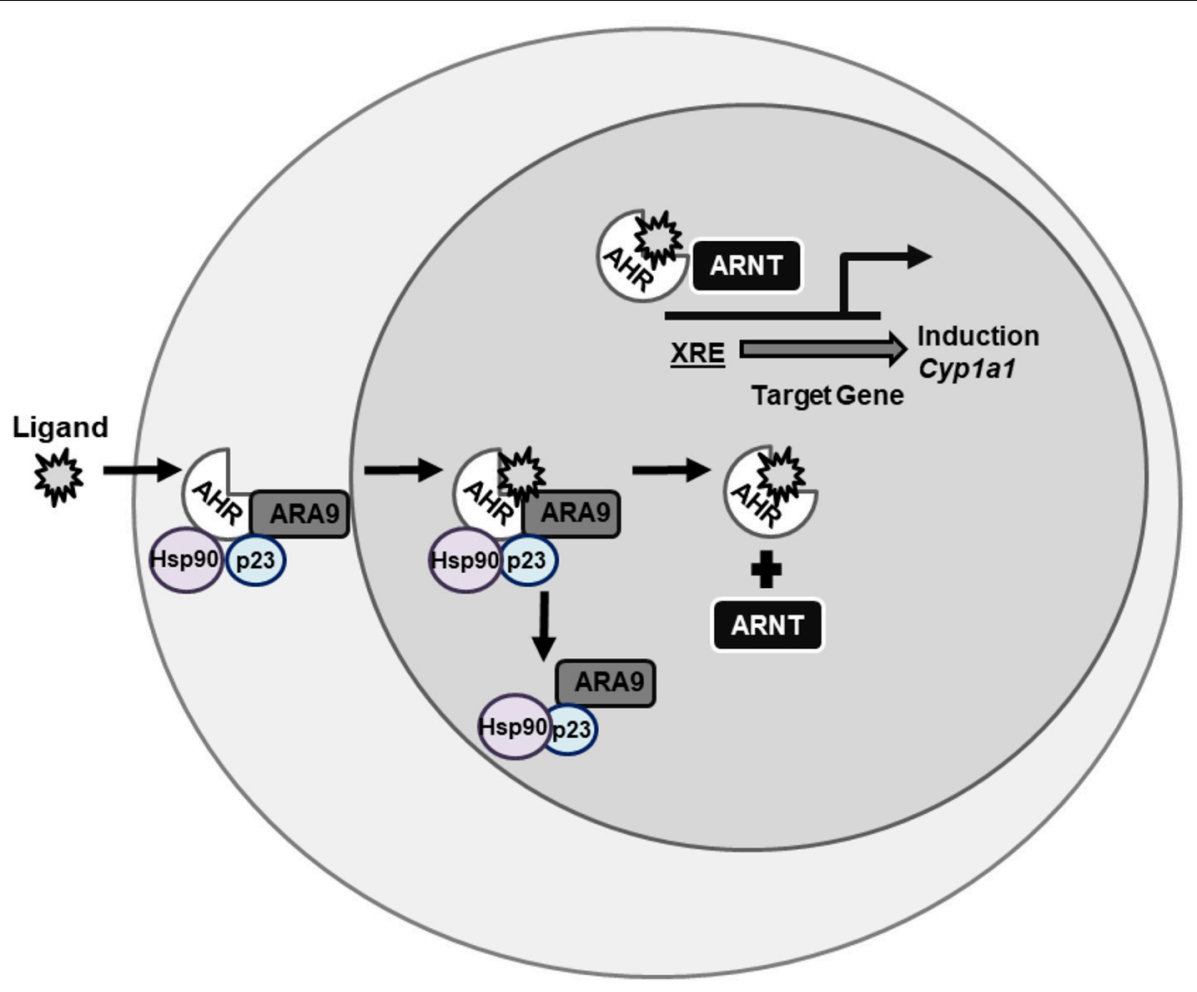

FIGURE 2 | AHR signaling pathway. AHR is a ligand-activated transcription factor the resides in the cytosol being held in conformation by chaperone proteins until bound by ligand. Once bound by ligand, AHR translocates to the nucleus, sheds its chaperone proteins, and binds ARNT. This complex then binds XREs on DNA and induces gene transcription of genes such as CYP1A1. AHR, aryl hydrocarbon receptor; ARNT, aryl hydrocarbon receptor nuclear translocator; XRE, xenobiotic response element; CYP, cytochrome P450.

repressor (152). The AHRR represses AHR transcriptional activity by competing with AHR for heterodimerization with ARNT and from AHRR-ARNT complex binding AHREs (152).

\section{THE ROLE OF AHR IN T CELLS}

AHR is critical in maintaining the balance between Th17 and Treg cells which play a major role in autoimmune disease. TCDD exposure, and subsequent AHR signaling, were shown to play a role in the generation of adaptive $\mathrm{CD} 4^{+} \mathrm{CD} 25^{+}$Tregs early in an immune response (153). Additionally, the expression of AHR on T cells was shown to be critical in blocking the generation of peripheral Tregs in the lower gastrointestinal tract after a bone marrow transplant, suggesting the AHR on donor T cells is essential for pathogenesis in acute graft vs. host disease (154). Quintana et al. (46) demonstrated that AHR directly controls $\mathrm{FOXP}^{+}{ }^{+}$Treg generation, by binding AHR binding sites on the Foxp3 gene. In addition, FICZ, in combination with Th17 promoting cytokines, enhanced Th17 differentiation in an AHR-dependent manner and interfered with the differentiation of Treg cells in vitro (46). Moreover, Veiga-Parga et al. (155) showed that a single administration of TCDD reduced severity of stromal keratitis lesions in the cornea by causing apoptosis of $\mathrm{FOXP}^{-} \mathrm{CD}^{+} \mathrm{T}$ cells but not $\mathrm{FOXP}^{+} \mathrm{CD}^{+}$Tregs.
TCDD also decreased the proliferation of FOXP3 $3^{-} \mathrm{CD} 4^{+} \mathrm{T}$ cells resulting in an increase in the ratio of Tregs to $\mathrm{T}$ effectors. In addition, in vitro studies revealed that TCDD addition to anti$\mathrm{CD} 3 / \mathrm{CD} 28$ stimulated naïve $\mathrm{CD} 4^{+} \mathrm{T}$ cells caused a significant induction of Tregs and inhibition of Th1 and Th17 differentiation (155).

In addition to TCDD, more natural AHR ligands, indole3-carbinol (I3C), 3,3'-diindolylmethane (DIM), ITE, and kynurenine, among others have been shown to promote Tregs, and FICZ to promote Th17 cells (46, 107, 156-159). Veldhoen et al. (44) demonstrated that AHR is most highly expressed in Th17 cells and AHR ligation by FICZ promotes Th17 differentiation, measured by an increase in percent of IL-17a and IL-22 positive cells, in an AHR-dependent manner. Moreover, Mezrich et al. (156) demonstrated that tryptophan breakdown product kynurenine activates the AHR leading to AHR-dependent Treg generation and has no effect on the generation of Th17 cells (156). Singh et al. (107) showed that treatment of C57BL/6 mice with I3C or DIM attenuated delayedtype hypersensitivity (DTH) response and generation of Th17 cells and promoted Tregs, whereas FICZ exacerbated the DTH response and promoted Th17 cells. Treatment with I3C or DIM decreased the induction of IL-17 but promoted IL-10 and FOXP3 expression in an AHR-dependent manner (107). In addition, Liu et al. (160) demonstrated that FICZ increased Th17 cells and 
decreased Treg cells, but naphthoflavone decreased Th17 and increased Treg cells.

One question that has emerged as a result of data showing different AHR ligands seem to have opposite effects on $\mathrm{T}$ cell differentiation, is whether the ability to elicit different effects is intrinsic to the ligand itself or specific to experimental features, such as route of exposure, AHR affinity, among others? Local administration of FICZ, combined in the emulsion with Complete Freund's adjuvant, worsened EAE $(44,46)$. However, Duarte et al. (102) demonstrated that systemic administration of FICZ by intraperitoneal injection resulted in partial inhibition of EAE, halfway to what was seen with TCDD. More recently, Erhlich et al. (161) used an acute alloresponse model and demonstrated that when dose and timing of administration of high-affinity AHR ligands was optimized for TCDD-equivalent Cyp1A1 induction, all ligands tested suppressed the alloresponse and induced Tr1 cells early on and Treg cells later. However, a low dose of FICZ led to transient Cyp1A1 mRNA expression, no suppression the alloresponse, and enhanced IL-17 production (161). Similar results were observed for low dose TCDD. Together these data demonstrate that route of exposure, dose and duration of AHR activation, and ligand affinity of AHR ligands drives the fate of $\mathrm{T}$ cell differentiation and leads to differential $\mathrm{T}$ cell effects in vivo (Table 1). This suggests that the differential immune responses observed are not intrinsic to each ligand, but rather a result of differential AHR activation.

In addition to FOXP3 ${ }^{+}$Tregs and Th17 cells, AHR has been shown to play a role in $\operatorname{Tr} 1$ cells which are FOXP3- regulatory $\mathrm{CD}^{+} \mathrm{T}$ cells that produce IL-10 and are generated by IL-27 and have non-redundant roles in the control of inflammation (162). IL-27 also suppresses the development of pathogenic IL17-producing CD4+ T cells Th17 cells (162). In human PBMCs, AHR promotes the differentiation of $\operatorname{Tr} 1$ cells and production of IL-10 through granzyme B (163). Additionally, Mascanfroni et al. demonstrated that at later time points in differentiation AHR promotes hypoxia inducible factor $1-\alpha$ (HIF1- $\alpha$ ) degradation and controls $\operatorname{Tr} 1$ cell metabolism.

\section{THE ROLE OF AHR IN AUTOIMMUNE DISEASE}

In the context of autoimmunity, activation of AHR by exogenous and endogenous ligands modulates $\mathrm{T}$ cell differentiation as well as effector and regulatory $\mathrm{T}$ cell function, and contributes to antigen presenting cell responses, all of which alter autoimmune diseases. In addition, AHR has been shown to differentially regulate these effector and regulatory $\mathrm{T}$ cells through both AHRE-mediated pathways, primarily for Th17, as well as nonAHRE mediated pathways, which have been shown to regulate Tregs (164). Given the complexity of AHR signaling and the differential regulation of $\mathrm{T}$ cells, the AHR has been studied as a candidate target for autoimmune disease.

Ishimaru et al. (104) demonstrated that three low dose TCDD exposures in neonatal mice disrupted thymic selection, enhanced production of Th1 cytokines from splenic CD4+ T cells, and increased autoantibodies in the sera of TCDD-exposed mice compared with those in control mice indicating that early exposure to environmental contaminants and consequent AHR signaling in the neonatal thymus alters differentiation and/or development of $\mathrm{T}$ cells associated with autoimmunity (104). In addition, Boule et al. (105) found that developmental exposure to TCDD and subsequent activation of AHR via lactation accelerated disease in $\mathrm{Gnaq}^{+/-}$mice, which are mice that are heterozygous for the $\mathrm{G} \alpha \mathrm{q}$ protein and have a genetic predisposition to develop an autoimmune disease with symptoms similar to SLE and RA, but are not guaranteed to develop disease. This accelerated disease correlated with increases in effector and regulatory $\mathrm{CD} 4^{+} \mathrm{T}$-cell populations in females as compared to males (105). Together these data imply a role of early environmental exposure with AHR-mediated autoimmune disease. It has been demonstrated that AHR ligands, including environmental toxicants, bind AHR and alter T cell development and function. In the context of autoimmune disease, AHR has been shown to play a role in T1D, RA, MS, and SLE by altering T cell functions.

\section{AHR and T1D}

One of the most commonly used mouse modes of type 1 diabetes is the non-obese diabetic (NOD) mouse, which develops spontaneous disease similar to humans, and females are most predominately affected (165). Diabetes in NOD mice is characterized by hyperglycemia and insulitis, leukocytic infiltration of the pancreatic islets, and decreases in pancreatic insulin $(165,166)$. Using NOD mice harboring a transgenic $\mathrm{T}$ cell receptor, Bellemore et al. (167) showed that IL-23 plus IL-6 driven Th17 differentiation of $\mathrm{CD}^{+}$cells results in production of large amounts of IL-22 and these cells induce T1D in young NOD mice upon adoptive transfer. Th17 cells polarized with TGF- $\beta$ plus IL-6 expressed AHR, IL-10, IL-21, and IL-9, and were able to suppress pathogenic Th17 cells in adoptive transfer experiments suggesting that regulatory $\mathrm{T}_{\text {reg }} 17$ cells induced by TGF- $\beta$ plus IL-6 express high levels of AHR and are protective while Th17 cells with a very low level of AHR induced by IL- 23 plus IL- 6 are pathogenic.

Kerkvliet et al. (103) found that chronic treatment of NOD mice with TCDD suppressed the development of autoimmune T1D, reduced pancreatic islet insulitis, and resulted in an expanded population of $\mathrm{CD}^{+}{ }^{+} \mathrm{CD} 25^{+} \mathrm{FOXP}^{+}$cells in the pancreatic lymph nodes. However, when TCDD treatment was stopped after 15 weeks, mice exhibited lower number of Tregs and decreased activation of AHR associated with development of diabetes over the next 8 months after treatment was terminated (103). Similarly, Ehrlich et al. (108) discovered that repeated oral dosing with the AHR ligand, 10-Cl-BBQ, suppressed infiltration in islet cells of NOD mice without clinical toxicity in an AHR-dependent manner and this was associated with increased frequency of $\mathrm{FOXP}^{+}$Tregs in the pancreas and pancreatic lymph nodes. Additionally, depletion of $\mathrm{FOXP}^{+}$cells did not abrogate immune suppression observed with $10-\mathrm{Cl}-\mathrm{BBQ}$ exposure, but reduction of effector $\mathrm{T}$ cells was sufficient to suppress disease suggesting 10-Cl-BBQ acts independently of FOXP3 ${ }^{+}$Tregs to suppress the development of pathogenic $\mathrm{T}$ cells (108). Additionally, Ehrlich et al. (117) discovered that in the 
absence of AHR, female NOD mice have a significantly reduced onset of diabetes in comparison to wild-type mice. A similar trend was observed between knockout and wild-type male mice suggesting AHR is important in the onset of T1D in NOD mice (117).

\section{AHR and RA}

RA results in an inflammatory milieu which causes primary human fibroblast-like synoviocytes (FLS) to undergo hyperplasia and ultimately lead to joint destruction. Lahoti et al. (118) demonstrated that co-treatment of FLS with the AHR antagonist, GNF351, repressed IL-1 $\beta$-induced cytokine and chemokine expression and inhibited the recruitment of AHR to the promoters of $I L-1 \beta$ and $I L-6$. In human FLS from patients with RA, the potent AHR antagonist, GNF351, attenuated IL-1 $\beta$ induced growth factor expression, IL-1 $\beta$-induced proliferation, protease-dependent invasion, and migration in RA-FLS in an AHR-dependent manner (119). Likewise, the percentage of AHR positive cells in PBMCs as well as AHR and CYP1A1 expression was higher in RA patients compared to healthy controls (168). Additionally, the percentage of $\mathrm{AHR}^{+} \mathrm{CD} 4^{+} \mathrm{CD} 25^{+} \mathrm{T}$ cell was significantly reduced in RA patients and the percentage of $\mathrm{AHR}^{+} \mathrm{CCR}^{+}{ }^{+} \mathrm{CD} 4^{+} \mathrm{T}$ cells was significantly increased in patients with RA (168).

Collagen-induced arthritis is a model of RA characterized by infiltration of macrophages and neutrophils into the joint, as well as T cell and B cell responses to type II collagen (169). The model involves immunizing genetically susceptible mice (DBA/1J) with a type II bovine collagen emulsion in complete Freund's adjuvant (CFA) or C57BL/6J mice with type II chicken collagen in CFA and giving a boost of type II bovine or type II chicken collagen in incomplete Freund's adjuvant (IFA) 21 days after the first injection (169). Mice typically develop disease 26 to 35 days after the initial injection (169). A rat model of collagen-induced arthritis involves immunizing with chicken type II collagen and CFA intradermally into the base of the tail on day 0 and a follow-up booster of chicken type II collagen in IFA on day 7 (170).

Isoquinoline alkaloids found in plants have been shown to have AHR activity and induce Tregs alleviating collagen-induced arthritis. Tong et al. (109) demonstrated that norisoboldine, an anti-arthritic isoquinoline alkaloid, functioned as an AHR ligand demonstrated by induction of CYP1A1 expression and activity, promotion of AHR/Hsp90 dissociation and AHR nuclear translocation, induction of AHRE reporter activity, and facilitation of AHR/AHRE binding and promoted intestinal Treg cell differentiation and function in an AHR-dependent manner. Additionally, adoptive transfer of Treg cells from norisoboldine treated mice alleviated arthritis in recipient collagen-induced arthritis mice (109). Similarly, tetrandrine, an alkaloid constituent, alleviated severity of arthritis, reduced serum levels of pro-inflammatory cytokines, and restored the Th17/Treg balance via the AHR, measured by serum levels of IL-17 and IL-10 respectively in collagen-induced arthritis mice (110). Likewise, Tong et al. (111) showed sinomenine, a plant alkaloid, induced the generation of intestinal Treg cells, and facilitated the immunosuppressive function of these
Treg cells in collagen-induced arthritis mice. The induction of intestinal Treg cells and the anti-arthritic effect of sinomenine in collagen-induced arthritis mice was diminished by the AHR antagonist resveratrol (111).

Nakahama et al. (115) used a murine collagen-induced arthritis model of RA and showed that AHR deficiency ameliorated collagen-induced arthritis and AHR null mice immunized with collagen showed decreased serum levels of proinflammatory cytokines IL- $1 \beta$ and IL- 6 . In addition, Th17 cells were decreased in the lymph nodes of AHR null mice whereas Th1 cells in lymph nodes were increased. This loss of AHR specifically in $\mathrm{T}$ cells suppressed collagen-induced arthritis development. Further supporting a role for AHR in RA, Talbot et al. (116) demonstrated that cigarette smoke, which contains AHR ligands like PAHs, induces arthritis aggravation and increases the frequency of Th17 cells. Mice null for IL-17 or AHR were protected from cigarette-smoking induced arthritis and exposure to PAHs aggravated arthritis suggesting that AHR ligands in cigarette smoke drive Th17 responses in vivo (116).

In RA, the shared epitope (SE), a five amino acid sequence motif encoded by RA-associated HLA-DRB1 is the most significant genetic risk factor. Fu et al. (106) showed that the SE and the AHR pathway exhibit a synergistic interaction dependent on nuclear factor kappa B (NF-kB) that results in osteoclast differentiation and Th17 polarization after exposure to FICZ or TCDD in bone marrow cells from transgenic mice carrying human SE-coding alleles. In vivo, exposure to FICZ or TCDD in transgenic mice carrying human SE-coding alleles resulted in a robust increase in arthritis severity, bone destruction, overabundance of osteoclasts, and infiltration of IL17-expressing cells in the inflamed joints and draining lymph nodes of arthritic mice (106).

\section{AHR and MS}

Experimental autoimmune encephalomyelitis (EAE) is an inflammatory demyelinating disease of the CNS in rodents that has similar pathologic and clinical symptoms to human MS. In C57BL/6J mice, the disease is induced by myelin oligodendrocyte (MOG) $)_{35-55}$ peptide and mediated by $\mathrm{CD} 4^{+} \mathrm{T}$ cells and macrophages (171). Initially, EAE was thought to be mediated by an exaggerated Th1 response, however deficiency in IL-12, and thus IFN $\gamma$ effector cells, exacerbated EAE (172). In contrast, mice deficient in IL-23, which promotes IL-17 effector cells, failed to develop EAE demonstrating IL-23, not IL-12 as the critical cytokine in autoimmune inflammation (172). Later, Park et al. (173) demonstrated that blocking IL-17 resulted in attenuation and delay of EAE and reversed the progression of active EAE and Harrington et al. (174) showed that IL-23induced, IL-17 producing $\mathrm{CD} 4^{+}$effector T cells have a distinct development program from Th1 or Th2 cells defining them as Th17 cells. Quintana et al. (46) demonstrated that intraperitoneal injection of TCDD shifts the balance toward Treg cells in vitro and in vivo and suppresses EAE whereas FICZ in the MOG $_{35-55}$ emulsion drives Th17 responses in vitro and in vivo and worsens severity of EAE (44). However, Duarte et al. (102) demonstrated that intraperitoneal administration of TCDD and FICZ lessened severity of EAE. Using EAE as a model, Kaye 
et al. (112) showed that laquinimod, an oral drug currently being evaluated for treatment of relapsing and remitting MS, induced genes associated with the AHR pathway such as Cyp1a1 and Ahrr in both naive and EAE mice treated with laquinimod in vitro and Cypla1 in vivo. Laquinimod treatment resulted in an AHR-dependent expansion of Tregs and reduction of effector T cells in EAE (112). O'Driscoll et al. (100) demonstrated that intranasal exposure to diesel PM samples, shown to enhance $T$ cell differentiation through the AHR, worsened severity of EAE, however exposure to its chemically-extracted OF resulted in one diesel OF worsening severity of EAE but the other lost this effect. O'Driscoll et al. (101) demonstrated that mice exposed intranasally to an ambient urban dust PM sample exhibited delayed disease onset and reduced severity of EAE and the delayed disease onset was AHR-dependent in vivo. Intranasal treatment to the ambient urban dust PM sample resulted in reduction of pathologic $\mathrm{T}$ cells in the CNS on day 10 after EAE induction and in a significant AHR-dependent reduction of IFN $\gamma$-producing $\mathrm{T}$ cells in an in vitro MOGspecific splenocyte assay (101). O'Driscoll et al. (101) identified the AHR pathway as a novel pathway through with PM can reduce Th1 responses in the CNS and although this suppression of Th1 cells may reduce severity of disease it opens the door for opportunistic infection if the immunosuppression in nonreversible. In humans, Rothhammer et al. (175) detected a global decrease of circulating AHR agonists in relapsing-remitting MS patients as compared to controls. However, increased AHR agonistic activity was observed during acute CNS inflammation in clinically isolated syndrome or active MS.

$\operatorname{Tr} 1$ cells are regulated by AHR and characterized as FOXP3 ${ }^{-} \mathrm{CD} 4^{+} \mathrm{T}$ cells that require IL-27, produce IL-10, and have been shown to prevent autoimmune disease. Apetoh et al. (176) demonstrated that AHR activation increased the production of IL-10 and IL-21, which acts as an autocrine growth factor for $\operatorname{Tr} 1$ cells, and mice with impaired AHR signaling exhibited decreased production of IL-10 and resistance to IL27-mediated inhibition of EAE (176). FOXP3 ${ }^{+}$Tregs are also modulated by AHR and play a role in autoimmune disease. Quintana et al. (113) found that AHR signaling participates in $\mathrm{FOXP}^{+}$Treg differentiation in vivo and treatment with the endogenous AHR ligand, ITE, given parenterally or orally induced FOXP3 ${ }^{+}$Tregs that suppressed EAE. Rouse et al. (114) demonstrated that pretreatment of EAE-induced mice with the endogenous AHR ligands, I3C and DIM completely prevented clinical symptoms and cellular infiltration into the CNS and posttreatment of EA- induced mice with I3C or DIM reduced severity of disease. In addition, I3C or DIM promoted the generation of Tregs, while down-regulating the induction of MOG-specific Th17 cells (114).

\section{AHR and SLE}

Rekik et al. (177) demonstrated that transcription of TGF- $\beta 1$ target genes are impaired in $\mathrm{CD}^{+} \mathrm{T}$ cells of active SLE patients and this impaired response to TGF- $\beta 1$ is associated with an overexpression of IL-22 in SLE patients suggesting that excessive activation of AHR pathway could inhibit the immunosuppressive effects of TGF- $\beta 1$ leading to exacerbated SLE. Similarly, Dorgham et al. (178) showed a significant expansion of Th17 and Th22 cells in the peripheral blood of active SLE patients, compared to inactive patients and controls. In addition, propranolol, a potential lupus-inducing drug, induced stronger AHR activation in PBMCs of SLE patients than in those of controls and SLE patients also exhibited signs of AHR activation in cutaneous tissues that correlated with lesion expression (178). Moreover, Shinde et al. (179) showed that an enhanced AHR transcriptional signature correlated with disease in patients with SLE. In murine SLE, strength of the AHR signal correlated with disease progression and disease course could be altered by modulating AHR activity (179).

\section{Summary: AHR Ligands and Autoimmune Disease}

Some AHR ligands have been shown to ameliorate autoimmune disease and others to exacerbate disease in vitro and in vivo (Table 1), but despite these differences it is clear that AHR ligands shift the balance between effector and regulatory $\mathrm{T}$ cells determining autoimmune disease outcomes. One question that has been raised is what gives certain ligands the ability to exacerbate disease vs. ameliorate disease? Previously it was thought that AHR regulated Th17 and Treg differentiation in vitro and in vivo in a ligand-specific manner $(44,46)$. This created a paradigm that TCDD promotes immunosuppression whereas endogenous ligands like FICZ promote Th17 responses exacerbating immune responses. However, Duarte et al. (102) demonstrated that AHR ligands can upregulate the Th17 program in vitro depending on AHR affinity and there are no ligand intrinsic modes of action differentiating one ligand from another. Moreover, in vivo the timing and mode of application as well as the differential susceptibility to metabolism by different ligands contributes to the immune response observed (102). More recently, it has been shown that extent and duration of AHR activation contribute to the immune effects observed (161). More specifically, if AHR activation was normalized to TCDD CYP1A1 mRNA induction levels in a model of graft vs. host disease, all ligands tested reduced severity of disease, but if lower levels of TCDD were given, along with other AHR ligands, the exposure increased Th17 cells and started to make disease worse (161). Together, these data suggest that extent and duration of AHR activation determine the immune effect elicited by specific ligands and that ligand-specific responses do not determine the immune responses. Cumulatively, these data demonstrate a clear role of AHR in autoimmune disease and indicate a likely role of AHR ligands present in PM in autoimmune disease.

\section{Linking PAHS and Autoimmune Disease}

PM contains many organic constituents which are AHR ligands that have the potential to contribute to autoimmunity. van Voorhis et al. (63) demonstrated that an individual $\mathrm{PAH}$, benzo[k]fluoranthene, enhanced Th17 differentiation in an AHR-dependent manner. Additionally, PM extracts and cigarette extracts, both of which contain PAHs, enhanced Th17 differentiation as well (63). Although this review focuses on the effects of PM and its constituents on autoimmune disease, it is worth noting that cigarette smoke also contains numerous PAHs 
at varying levels and there are several epidemiological studies that demonstrate an increased risk of autoimmune diseases such as RA, MS, and SLE in individuals who smoke cigarettes (180185) and using animal models, Talbot et al. (116) demonstrated that cigarette smoke, which contains AHR ligands like PAHs, aggravates arthritis and increases the frequency of Th17 cells. Furthermore, O'Driscoll et al. (100) demonstrated that synthetic PAH mixtures based on the milieu of 15 PAHs present in standard PM samples enhanced Th17 differentiation via the AHR and/or CYP metabolism. The combination of epidemiological data that associated PM, as well as cigarette smoke, with increased risk and/or exacerbated autoimmune diseases and the in vitro studies in mice that demonstrated PM and its chemically-extracted organic fraction $(63,100)$, cigarette smoke extract $(63)$, individual PAHs (63), and synthetic PAH mixtures (100), enhanced Th17 differentiation suggest that PAHs present in PM are candidate components that may activate the AHR, shift T cell balances, and alter autoimmune disease status.

\section{Closing the Gap}

The incidence and prevalence of autoimmune diseases is continuing to rise and although a clear genetic component exists, environmental factors also contribute to autoimmune diseases. Epidemiologic studies strongly suggest that exposure to PM can increase both incidence and severity of autoimmune disease. Exposure to PM has been associated with aggravation of autoimmune diseases including T1D, MS, RA, and SLE. These autoimmune diseases also have a clear autoreactive $\mathrm{T}$ cell component to their pathology. Although a clear role for autoreactive $\mathrm{T}$ cells has been established, identifying specific exposures and mechanisms leading to autoimmune disease process has proven particularly difficult.

PM activates the AHR and induces the production of inflammatory cytokines in immune cells. The AHR can modulate $\mathrm{T}$ cells responses by shifting the balance between regulatory and effector responses. Both PM and the AHR have strong associations with autoreactive $\mathrm{T}$ cells and autoimmune disease (Table 1). Additionally, PM exposures act through the AHR altering $\mathrm{T}$ cell responses in vitro and in vivo changing autoimmune disease pathology (Table 1). The AHR responds to several environmental toxicants found in PM, such as PAHs, and PM exposures alter T cell balance and autoimmune disease via the AHR. Moreover, the contradictory epidemiologic data could be explained by differences in AHR ligands present in the PM and the extent and duration of activation of the AHR. This leads us to the novel hypothesis that AHR ligands present in PM activate the AHR, shift the T cell balance, and lead to PM-mediated autoimmune disease. We propose a hypothesis in which AHR ligands, such as PAHs, adhered to atmospheric PM activate the AHR and upregulate CYP enzymes [Figure 3 adapted from O'Driscoll et al. (100)]. The extent and duration of AHR activation by AHR ligands adhered to PM shifts the $\mathrm{T}$ cell response resulting in an effector $\mathrm{T}$ cell response that is suppressed and ameliorates autoimmunity or enhanced and aggravates autoimmunity [Figure 3 adapted from O'Driscoll et al. (100)]. Additionally, AHR ligands may become bioavailable either while adhered to the PM or after getting removed from the PM. Once bioavailable, the ligands have the capacity to get metabolized by CYP enzymes and this metabolism can play a role aggravating autoimmune disease [Figure 3 adapted from

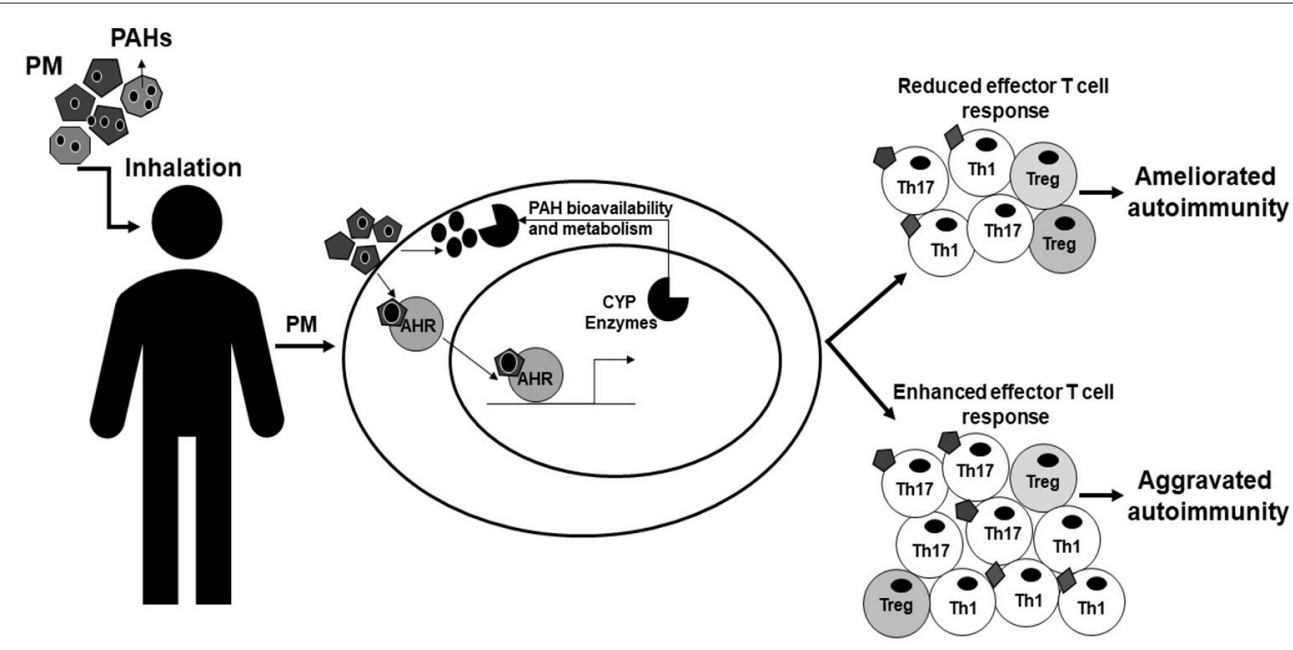

FIGURE 3 | Model of AHR modulation of PM-mediated autoimmunity. This figure is adapted from O'Driscoll et al. (100) and demonstrates how AHR may modulate PM-mediated autoimmunity. PM is inhaled by people and once inhaled is able to be taken-up and has the capacity to activate the AHR in cells within the body. AHR ligands, such as PAHs, adhered to atmospheric PM activate the AHR and cause the AHR to translocate to the nucleus and bind DNA elements such as XRE, inducing genes including CYP enzymes. The extent and duration of activation of AHR ligands shifts the immune balance enhancing effector $\mathrm{T}$ cells worsening autoimmunity or suppressing $T$ cell responses and ameliorating autoimmunity. The AHR ligands adhered to the particulate have the potential to become bioavailable through metabolism or other mechanisms and then can be metabolized by CYP enzymes potentially causing other immune related effects or altering the immune responses. AHR, aryl hydrocarbon receptor; PM, particulate matter; PAHs, polycyclic aromatic hydrocarbons; XRE, xenobiotic response element; CYP, cytochrome P450. This figure or a version of this figure was published in Particle and Fibre and Toxicology and is licensed under the Creative Commons Attribution 4.0 International Public License. 
O'Driscoll et al. (100)]. The identification of components of PM that activate the AHR and also specific AHR pathway targets that can shift the immune balance from inflammatory to regulatory are crucial for understanding the mechanisms through which the AHR contributes to PM-mediated autoimmune disease. PM contains multiple AHR ligands and thus understanding the specific ligands and pathways involved in autoimmune disease could lend insight into the environmental component of autoimmune pathology. Although the AHR is unlikely to be the whole story, it may be a start to identifying mechanisms to alleviate symptoms of autoimmune disease as well as prevent disease all together. Future studies should investigate (1) the AHR ligands present in PM and how they alter T cell response and (2) the specific AHR pathway components required for responses in order to generate therapies to decrease autoimmune

\section{REFERENCES}

1. Miller FW, Alfredsson L, Costenbader KH, Kamen DL, Nelson LM, Norris JM, et al. Epidemiology of environmental exposures and human autoimmune diseases: findings from a National Institute of Environmental Health Sciences Expert Panel Workshop. J Autoimmun. (2012) 39:259-71. doi: 10.1016/j.jaut.2012.05.002

2. Cooper GS, Bynum MLK, Somers EC. Recent insights in the epidemiology of autoimmune diseases. Improved prevalence estimates and understanding of clustering of diseases. J Autoimmun. (2009) 33:197-207 doi: 10.1016/j.jaut.2009.09.008

3. Lerner A, Jeremias $P$, and Matthias, $T$. The world incidence and prevalence of autoimmune diseases is increasing. Int J Celiac Dis. (2015) 3:151-5. doi: $10.12691 /$ ijcd-3-4-8

4. NIO Health. Progress in autoimmune disease research. In: The Autoimmune Diseases Coordinating Committee. Bethesda: National Institute of Health (2005). p. 1-146.

5. Cooper GS, Stroehla BC. The epidemiology of autoimmune diseases. Autoimmun Rev. (2003) 2:119-25. doi: 10.1016/S1568-9972(03)00006-5

6. Goverman J. Autoimmune T cell responses in the central nervous system. Nat Rev Immunol. (2009) 9:393. doi: 10.1038/nri2550

7. Suarez-Fueyo A, Bradley SJ, Tsokos GC. T cells in systemic lupus erythematosus. Curr Opin Immunol. (2016) 43:32-8. doi: 10.1016/j.coi.2016.09.001

8. Cope AP, Schulze-Koops H, Aringer M. The central role of $\mathrm{T}$ cells in rheumatoid arthritis. Clin Exp Rheumatol. (2007) 25:S4-11.

9. Pugliese A. Autoreactive T cells in type 1 diabetes J Clin Invest. (2017) 127:2881-91. doi: 10.1172/JCI94549

10. Fletcher JM, Lalor SJ, Sweeney CM, Tubridy N, Mills KHG. T cells in multiple sclerosis and experimental autoimmune encephalomyelitis. Clin Exp Immunol. (2010) 162:1-11. doi: 10.1111/j.1365-2249.2010.04143.x

11. Rosenblum MD, Remedios KA, Abbas AK. Mechanisms of human autoimmunity. J Clin Invest. (2015) 125:2228-33. doi: 10.1172/JCI78088

12. Vojdani A, Pollard KM, Campbell AW. Environmental triggers and autoimmunity. Autoimmune Dis. (2014) 2014:798029. doi: $10.1155 / 2014 / 798029$

13. Seldin MF. The genetics of human autoimmune disease: a perspective on progress in the field and future directions. J Autoimmun. (2015) 64:1-12. doi: 10.1016/j.jaut.2015.08.015

14. Institute HE. State of Global Air 2018. In: Health Effects Institute, Boston, MA (2018).

15. Brauer M, Freedman G, Frostad J, van Donkelaar A, Martin RV, Dentener $\mathrm{F}$, et al. Ambient air pollution exposure estimation for the global burden of disease 2013. Environ Sci Technol. (2016) 50:79-88. doi: 10.1021/acs.est.5b03709

16. Beyerlein A, Krasmann M, Thiering E, Kusian D, Markevych I, D’Orlando $\mathrm{O}$, et al. Ambient air pollution and early manifestation of type 1 disease and hopefully prevent disease onset secondary to PM exposure.

\section{AUTHOR CONTRIBUTIONS}

$\mathrm{CO}$ and JM wrote the manuscript. All authors read and approved the final manuscript.

\section{FUNDING}

This work was supported by the National Institute of Environmental Health Sciences (NIEHS). [RO1 ES023842 to JM, R21 ES025304 to JM], and [T32 ES007015 (CO)]. Its contents are solely the responsibility of the authors and do not necessarily represent the official views of the NIEHS. diabetes. Epidemiology (2015) 26:e31-2. doi: 10.1097/EDE.00000000000 00254

17. Brook RD, Cakmak S, Turner MC, Brook JR, Crouse DL, Peters PA, et al. T. Long-term fine particulate matter exposure and mortality from diabetes in Canada. Diabetes Care (2013) 36:3313-20. doi: 10.2337/dc12-2189

18. Di Ciaula A. Type I diabetes in paediatric age in Apulia (Italy): Incidence and associations with outdoor air pollutants. Diabetes Res Clin Pract. (2016) 111:36-43. doi: 10.1016/j.diabres.2015.10.016

19. Gonzalez RN, Torres-Aviles F, Carrasco PE, Salas PF, Perez BF. [Association of the incidence of type 1 diabetes mellitus with environmental factors in Chile during the period 2000-2007]. Rev Med Chil. (2013) 141:595-601. doi: $10.4067 /$ S0034-98872013000500007

20. Hathout EH, Beeson WL, Nahab F, Rabadi A, Thomas W, Mace JW. Role of exposure to air pollutants in the development of type 1 diabetes before and after $5 \mathrm{yr}$ of age. Pediatr Diabetes (2002) 3:184-8. doi: 10.1034/j.1399-5448.2002.30403.x

21. Malmqvist E, Larsson HE, Jonsson I, Rignell-Hydbom A, Ivarsson SA, Tinnerberg $\mathrm{H}$, et al. Maternal exposure to air pollution and type 1 diabetes-Accounting for genetic factors. Environ Res. (2015) 140:268-74. doi: 10.1016/j.envres.2015.03.024

22. Angelici L, Piola M, Cavalleri T, Randi G, Cortini F, Bergamaschi R, et al. Effects of particulate matter exposure on multiple sclerosis hospital admission in Lombardy region, Italy. Environ Res. (2016) 145:68-73. doi: 10.1016/j.envres.2015.11.017

23. Gregory AC, Shendell DG, Okosun IS, Gieseker KE. Multiple sclerosis disease distribution and potential impact of environmental air pollutants in Georgia. Sci Total Environ. (2008) 396:42-51. doi: 10.1016/j.scitotenv.2008.01.065

24. Oikonen M, Laaksonen M, Laippala P, Oksaranta O, Lilius EM, Lindgren $\mathrm{S}$, et al. Ambient air quality and occurrence of multiple sclerosis relapse. Neuroepidemiology (2003) 22:95-9. doi: 10.1159/000067108

25. Roux J, Bard D, Le Pabic E, Segala C, Reis J, Ongagna JC, et al. Air pollution by particulate matter PM10 may trigger multiple sclerosis relapses. Environ Res. (2017) 156:404-10. doi: 10.1016/j.envres.2017.03.049

26. Vojinovic S, Savic D, Lukic S, Savic L, Vojinovic J. Disease relapses in multiple sclerosis can be influenced by air pollution and climate seasonal conditions. Vojnosanit Pregl (2015) 72:44-9. doi: 10.2298/VSP140121030V

27. Chang KH, Hsu CC, Muo CH, Hsu CY, Liu HC, Kao CH, et al. Air pollution exposure increases the risk of rheumatoid arthritis: A longitudinal and nationwide study. Environ Int. (2016) 94:495-9. doi: 10.1016/j.envint.2016.06.008

28. Vidotto JP, Pereira LA, Braga AL, Silva CA, Sallum AM, Campos LM, et al. Atmospheric pollution: influence on hospital admissions in paediatric rheumatic diseases. Lupus (2012) 21:526-33. doi: $10.1177 / 0961203312437806$

29. Bernatsky S, Fournier M, Pineau CA, Clarke AE, Vinet E, Smargiassi A. Associations between ambient fine particulate levels and disease activity in 
patients with systemic lupus erythematosus (SLE). Environ Health Perspect. (2011) 119:45-9. doi: 10.1289/ehp.1002123

30. Bernatsky S, Smargiassi A, Johnson M, Kaplan GG, Barnabe C, Svenson $\mathrm{L}$, et al. Fine particulate air pollution, nitrogen dioxide, and systemic autoimmune rheumatic disease in Calgary, Alberta. Environ Res. (2015) 140:474-8. doi: 10.1016/j.envres.2015.05.007

31. Bernatsky S, Smargiassi A, Barnabe C, Svenson LW, Brand A, Martin RV, et al. Fine particulate air pollution and systemic autoimmune rheumatic disease in two Canadian provinces. Environ Res. (2016) 146:85-91. doi: 10.1016/j.envres.2015.12.021

32. Fernandes EC, Silva CA, Braga AL, Sallum AM, Campos LM, Farhat SC. Exposure to air pollutants and disease activity in juvenile-onset systemic lupus erythematosus patients. Arthritis Care Res. (2015) 67:160914. doi: $10.1002 /$ acr. 22603

33. Farhat SC, Silva CA, Orione MA, Campos LM, Sallum AM, Braga AL. Air pollution in autoimmune rheumatic diseases: a review. Autoimmun Rev. (2011) 11:14-21. doi: 10.1016/j.autrev.2011.06.008

34. Gawda A, Majka G, Nowak B, Marcinkiewicz J. Air pollution, oxidative stress, and exacerbation of autoimmune diseases. Cent Eur J Immunol. (2017) 42:305-12. doi: 10.5114/ceji.2017.70975

35. Kelly FJ, Fussell JC. Size, source and chemical composition as determinants of toxicity attributable to ambient particulate matter. Atmospheric Environ. (2012) 60:504-26. doi: 10.1016/j.atmosenv.2012.06.039

36. National Research Council. Global Sources of Local Pollution: An Assessment of Long-Range Transport of Key Air Pollutants to and From the United States. Washington, DC: TNA Press (2010).

37. Cheung K, Daher N, Kam W, Shafer MM, Ning Z, Schauer JJ, et al. Spatial and temporal variation of chemical composition and mass closure of ambient coarse particulate matter (PM10-2.5) in the Los Angeles area. Atmos Environ. (2011) 45:2651-62. doi: 10.1016/j.atmosenv.2011.02.066

38. Vincent R, Bjarnason SG, Adamson IY, Hedgecock C, Kumarathasan P, Guénette J, et al. Acute pulmonary toxicity of urban particulate matter and ozone. Am J Pathol. (1997) 151:1563-70.

39. USEP Agency. Health Assessment Document for Diesel Engine Exhaust (Final 2002). Washington, DC: US Environmental Protection Agency; National Center for Environmental Assessment; EPA, Washington Office (2002).

40. DeGroot D, He G, Fraccalvieri D, Bonati L, Pandini A, Denison M. AhR ligands: promiscuity in binding and diversity in response. In: Pohjanvirta $\mathrm{R}$, editor. The AH Receptor in Biology and Toxicology. Hoboken, NJ: Wiley (2011).

41. Denison MS, Nagy SR. Activation of the aryl hydrocarbon receptor by structurally diverse exogenous and endogenous chemicals. Annu Rev Pharmacol Toxicol. (2003) 43:309-34. doi: 10.1146/annurev.pharmtox.43.100901.135828

42. White SS, Birnbaum LS. An overview of the effects of dioxins and dioxinlike compounds on vertebrates, as documented in human and ecological epidemiology. J Environ Sci Health C Environ Carcinog Ecotoxicol Rev. (2009) 27:197-211. doi: 10.1080/10590500903310047

43. Stockinger B, Di Meglio P, Gialitakis M, Duarte JH. The aryl hydrocarbon receptor: multitasking in the immune system. Annu Rev Immunol. (2014) 32:403-32. doi: 10.1146/annurev-immunol-032713-120245

44. Veldhoen M, Hirota K, Westendorf AM, Buer J, Dumoutier L, Renauld JC, et al. The aryl hydrocarbon receptor links TH17-cell-mediated autoimmunity to environmental toxins. Nature (2008) 453:106-9. doi: 10.1038 /nature06881

45. Mascanfroni ID, Takenaka MC, Yeste A, Patel B, Wu Y, Kenison JE, et al. Metabolic control of type 1 regulatory T cell differentiation by AHR and HIF1-alpha. Nat Med. (2015) 21:638-46. doi: 10.1038/nm.3868

46. Quintana FJ, Basso AS, Iglesias AH, Korn T, Farez MF, Bettelli E, et al. Control of $\mathrm{T}(\mathrm{reg})$ and $\mathrm{T}(\mathrm{H}) 17$ cell differentiation by the aryl hydrocarbon receptor. Nature (2008) 453:65-71. doi: 10.1038/nature06880

47. Nguyen LP, Bradfield CA. The search for endogenous activators of the aryl hydrocarbon receptor. Chem Res Toxicol. (2008) 21:102-16. doi: $10.1021 /$ tx7001965

48. Griesemer AD, Sorenson EC, Hardy MA. The role of the thymus in tolerance. Transplantation (2010) 90:465-74. doi: 10.1097/TP.0b013e3181e7e54f

49. Charles J, Janeway A, Travers P, Walport M, Shlomchik MJ. Self-Tolerance and Its Loss. Garland Science (2001).
50. Sojka DK, Huang YH, Fowell DJ. Mechanisms of regulatory T-cell suppression - a diverse arsenal for a moving target. Immunology (2008) 124:13-22. doi: 10.1111/j.1365-2567.2008.02813.x

51. Dardalhon V, Korn T, Kuchroo VK, Anderson AC. Role of Th1 and Th17 cells in organ-specific autoimmunity. J Autoimmun. (2008) 31:252-6. doi: 10.1016/j.jaut.2008.04.017

52. Langrish CL, Chen Y, Blumenschein WM, Mattson J, Basham B, Sedgwick JD, et al. IL-23 drives a pathogenic T cell population that induces autoimmune inflammation. J Exp Med. (2005) 201:233-40. doi: 10.1084/jem.200 41257

53. Komatsu N, Okamoto K, Sawa S, Nakashima TM, Oh-hora, KT, Tanaka $\mathrm{S}$, et al. Pathogenic conversion of Foxp3+ T cells into TH17 cells in autoimmune arthritis. Nat Med. (2014) 20:62-8. doi: 10.1038/nm.3432

54. Burkett PR, Horste GMz, Kuchroo VK. Pouring fuel on the fire: Th17 cells, the environment, and autoimmunity. J Clin Invest. (2015) 125:2211-9. doi: 10.1172/JCI78085

55. Bell ML. Assessment of the Health Impacts of Particulate Matter Characteristics. Boston, MA: Health Effects Institute (2012).

56. Anderson JO, Thundiyil JG, Stolbach A. Clearing the air: a review of the effects of particulate matter air pollution on human health. J Med Toxicol. (2012) 8:166-75. doi: 10.1007/s13181-011-0203-1

57. DeCarlo PF, Slowik JG, Worsnop DR, Davidovits P, Jimenez JL. Particle Morphology and Density Characterization by Combined Mobility and Aerodynamic Diameter Measurements. Part 1: Theory. Aerosol Sci Technol. (2012) 38:1185-205. doi: 10.1080/027868290903907

58. Griffin RJ. The sources and impacts of tropospheric particulate matter. Nat Educ Knowledge (2013) 4:1.

59. Pierdominici M, Maselli A, Cecchetti S, Tinari A, Mastrofrancesco A, Alfe $M$, et al. Diesel exhaust particle exposure in vitro impacts $T$ lymphocyte phenotype and function. Part Fibre Toxicol. (2014) 11:74. doi: 10.1186/s12989-014-0074-0

60. Nakamura R, Inoue K, Fujitani Y, Kiyono M, Hirano S, Takano. H. Effects of nanoparticle-rich diesel exhaust particles on IL-17 production in vitro. $J$ Immunotoxicol. (2012) 9:72-6. doi: 10.3109/1547691X.2011.629638

61. Ma QY, Huang DY, Zhang HJ, Wang S, Chen XF. Exposure to particulate matter 2.5 (PM2.5) induced macrophage-dependent inflammation, characterized by increased Th1/Th17 cytokine secretion and cytotoxicity. Int Immunopharmacol. (2017) 50:139-45. doi: 10.1016/j.intimp.2017. 06.019

62. Deiuliis JA, Kampfrath T, Zhong J, Oghumu S, Maiseyeu A, Chen LC, et al. Pulmonary T cell activation in response to chronic particulate air pollution. Am J Physiol Lung Cell Mol Physiol. (2012) 302:L399-409. doi: 10.1152/ajplung.00261.2011

63. van Voorhis M, Knopp S, Julliard W, Fechner JH, Zhang X, Schauer JJ, et al. Exposure to atmospheric particulate matter enhances Th17 polarization through the aryl hydrocarbon receptor. PLOS ONE (2013) 8:e82545. doi: 10.1371/journal.pone.0082545

64. Castaneda AR, Pinkerton KE, Bein KJ, Magana-Mendez A, Yang HT, Ashwood P, et al. Ambient particulate matter activates the aryl hydrocarbon receptor in dendritic cells and enhances Th17 polarization. Toxicol Lett. (2018) 292:85-96. doi: 10.1016/j.toxlet.2018.04.020

65. Atkinson MA, Eisenbarth GS, Michels AW. Type 1 diabetes. Lancet (2014) 383:69-82. doi: 10.1016/S0140-6736(13)60591-7

66. Schneider A, Rieck M, Sanda S, Pihoker C, Greenbaum C, Buckner $\mathrm{JH}$. The effector $\mathrm{T}$ cells of diabetic subjects are resistant to regulation via CD4+ FOXP3+ regulatory T cells. J Immunol. (2008) 181:7350-5. doi: 10.4049/jimmunol.181.10.7350

67. Ferraro A, Socci C, Stabilini A, Valle A, Monti P, Piemonti L, et al. Expansion of Th17 cells and functional defects in T regulatory cells are key features of the pancreatic lymph nodes in patients with type 1 diabetes (2011) 60:2903-13. doi: 10.2337/db11-0090

68. Maahs DM, West NA, Lawrence JM, Mayer-Davis EJ. Chapter 1: epidemiology of type 1 diabetes. Endocrinol Metab Clin North Am. (2010) 39:481-97. doi: 10.1016/j.ecl.2010.05.011

69. Patterson CC, Dahlquist GG, Gyurus E, Green A, Soltesz G. Incidence trends for childhood type 1 diabetes in Europe during 1989-2003 and predicted new cases 2005-20: a multicentre prospective registration study. Lancet (2009) 373:2027-33. doi: 10.1016/S0140-6736(09)60568-7 
70. Hathout EH, Beeson WL, Ischander M, Rao R, Mace JW. Air pollution and type 1 diabetes in children. Pediatr Diabetes (2006) 7:81-7. doi: 10.1111/j.1399-543X.2006.00150.x

71. Michalska M, Bartoszewicz M, Waz P, Kozaczuk S, Ben-Skowronek I, Zorena K. PM10 concentration and microbiological assessment of air in relation to the number of acute cases of type 1 diabetes mellitus in the Lubelskie Voivodeship. Preliminary report. Pediatr Endocrinol Diabetes Metab. (2017) 23:70-6. doi: 10.18544/PEDM-23.02.0076

72. Yitshak Sade M, Kloog I, Liberty IF, Schwartz J, Novack V. The association between air pollution exposure and glucose and lipids levels. J Clin Endocrinol Metab. (2016) 101:2460-7. doi: 10.1210/jc.2016-1378

73. Lanzinger S, Rosenbauer J, Sugiri D, Schikowski T, Treiber B, Klee D, et al. Impact of long-term air pollution exposure on metabolic control in children and adolescents with type 1 diabetes: results from the DPV registry. Diabetologia (2018) 61:1354-61. doi: 10.1007/s00125-0184580-8

74. Feldmann M, Brennan FM, Maini RN. Rheumatoid arthritis. Cell (1996) 85:307-10. doi: 10.1016/S0092-8674(00)81109-5

75. Brennan FM, McInnes IB. Evidence that cytokines play a role in rheumatoid arthritis. J Clin Invest. (2008) 118:3537-45. doi: 10.1172/JCI36389

76. Hart JE, Laden F, Puett RC, Costenbader KH, Karlson EW. Exposure to traffic pollution and increased risk of rheumatoid arthritis. Environ Health Perspect. (2009) 117:1065-9. doi: 10.1289/ehp.0800503

77. Hoovestol RA, Mikuls TR. Environmental exposures and rheumatoid arthritis risk. Curr Rheumatol Rep. (2011) 13:431-9. doi: 10.1007/s11926-011-0203-9

78. De Roos AJ, Koehoorn M, Tamburic L, Davies HW, Brauer M. Proximity to traffic, ambient air pollution, and community noise in relation to incident rheumatoid arthritis. Environ Health Perspect. (2014) 122:1075-80. doi: 10.1289/ehp.1307413

79. Hart JE, Källberg H, Laden F, Costenbader KH, Yanosky JD, Klareskog $\mathrm{L}$, et al. Ambient air pollution exposures and risk of rheumatoid arthritis in the Nurses' Health Study. Arthritis Care Res. (2013) 65:1190-6. doi: 10.1002/acr.21975

80. Hart JE, Kallberg H, Laden F, Bellander T, Costenbader KH, Holmqvist $\mathrm{M}$, et al. Ambient air pollution exposures and risk of rheumatoid arthritis: results from the Swedish EIRA case-control study. Ann Rheum Dis. (2013) 72:888-94. doi: 10.1136/annrheumdis-2012-201587

81. Chiang YC, Yen YH, Chang WC, Cheng KJ, Chang WP, Chen HY. The association between urbanization and rheumatoid arthritis in Taiwan. Int J Clin Pharmacol Ther. (2016) 54:1-10. doi: 10.5414/CP202306

82. Sigaux J, Biton J, Andre E, Semerano L, Boissier MC. Air pollution as a determinant of rheumatoid arthritis. Joint Bone Spine (2018) doi: 10.1016/j.jbspin.2018.03.001

83. Gan RW, Deane KD, Zerbe GO, Demoruelle MK, Weisman MH, Buckner $\mathrm{JH}$, et al. Relationship between air pollution and positivity of RA-related autoantibodies in individuals without established RA: a report on SERA. Ann Rheum Dis. (2013) 72:2002-5. doi: 10.1136/annrheumdis-2012-202949

84. Sun G, Hazlewood G, Bernatsky S, Kaplan GG, Eksteen B, Barnabe C. Association between air pollution and the development of rheumatic disease: a systematic review. Int J Rheumatol. (2016) 2016:5356307. doi: 10.1155/2016/5356307

85. Zeft AS, Prahalad S, Lefevre S, Clifford B, McNally B, Bohnsack JF, et al. Juvenile idiopathic arthritis and exposure to fine particulate air pollution. Clin Exp Rheumatol. (2009) 27:877-84.

86. Zeft AS, Prahalad S, Schneider R, Dedeoglu F, Weiss PF, Grom AA, et al. Systemic onset juvenile idiopathic arthritis and exposure to fine particulate air pollution. Clin Exp Rheumatol. (2016) 34:946-52.

87. Compston A, Coles A. Multiple sclerosis. Lancet (2008) 372:1502-17. doi: 10.1016/S0140-6736(08)61620-7

88. Oikonen MK, Eralinna JP. Beta-interferon protects multiple sclerosis patients against enhanced susceptibility to infections caused by poor air quality. Neuroepidemiology (2008) 30:13-9. doi: 10.1159/000113301

89. Jeanjean M, Bind MA, Roux J, Ongagna JC, de Seze J, Bard D, et al. Ozone, NO2 and PM10 are associated with the occurrence of multiple sclerosis relapses. Evidence from seasonal multi-pollutant analyses. Environ Res. (2018) 163:43-52. doi: 10.1016/j.envres.2018.01.040
90. Heydarpour P, Amini H, Khoshkish S, Seidkhani H, Sahraian MA, Yunesian M. Potential impact of air pollution on multiple sclerosis in Tehran, Iran. Neuroepidemiology (2014) 43:233-8. doi: 10.1159/000368553

91. Lavery AM, Waldman AT, Charles Casper T, Roalstad S, Candee M, Rose J, et al. Examining the contributions of environmental quality to pediatric multiple sclerosis. Mult Scler Relat Disord. (2017) 18:164-9. doi: 10.1016/j.msard.2017.09.004

92. Bergamaschi R, Cortese A, Pichiecchio A, Berzolari FG, Borrelli P, Mallucci $\mathrm{G}$, et al. Air pollution is associated to the multiple sclerosis inflammatory activity as measured by brain MRI. Mult Scler. (2018) 24:1578-84. doi: $10.1177 / 1352458517726866$

93. Klocke C, Allen JL, Sobolewski M, Mayer-Proschel M, Blum JL, Lauterstein $\mathrm{D}$, et al. Neuropathological consequences of gestational exposure to concentrated ambient fine and ultrafine particles in the mouse. Toxicol Sci. (2017) 156:492-508. doi: 10.1093/toxsci/kfx010

94. Klocke C, Allen JL, Sobolewski M, Blum JL, Zelikoff JT, CorySlechta DA. Exposure to fine and ultrafine particulate matter during gestation alters postnatal oligodendrocyte maturation, proliferation capacity, and myelination. Neurotoxicology (2018) 65:196-206. doi: 10.1016/j.neuro.2017.10.004

95. Palacios N, Munger KL, Fitzgerald KC, Hart JE, Chitnis T, Ascherio A, et al. Exposure to particulate matter air pollution and risk of multiple sclerosis in two large cohorts of US nurses. Environ Int. (2017) 109:64-72. doi: 10.1016/j.envint.2017.07.013

96. Chen H, Kwong JC, Copes R, Tu K, Villeneuve PJ, van Donkelaar A, et al. Living near major roads and the incidence of dementia, Parkinson's disease, and multiple sclerosis: a population-based cohort study. Lancet (2017) 389:718-26. doi: 10.1016/S0140-6736(16)32399-6

97. Carmona R, Linares C, Recio A, Ortiz C, Diaz J. Emergency multiple sclerosis hospital admissions attributable to chemical and acoustic pollution: Madrid (Spain), 2001-2009. Sci Total Environ. (2018) 612:111-8. doi: 10.1016/j.scitotenv.2017.08.243

98. Tsokos GC. Systemic lupus erythematosus. N Engl J Med. (2011) 365:2110-21. doi: 10.1056/NEJMra1100359

99. Bernatsky S, Joseph L, Pineau CA, Tamblyn R, Feldman DE, Clarke AE. A population-based assessment of systemic lupus erythematosus incidence and prevalence-results and implications of using administrative data for epidemiological studies. Rheumatology (2007) 46:1814-8. doi: 10.1093/rheumatology/kem233

100. O’Driscoll CA, Owens LA, Gallo ME, Hoffmann EJ, Afrazi A, Han $\mathrm{M}$, et al. Differential effects of diesel exhaust particles on $\mathrm{T}$ cell differentiation and autoimmune disease. Part Fibre Toxicol. (2018) 15:35. doi: 10.1186/s12989-018-0271-3

101. O'Driscoll CA, Owens LA, Hoffmann EJ, Gallo ME, Afrazi A, et al. Ambient urban dust particulate matter reduces pathologic $\mathrm{T}$ cells in the CNS and severity of EAE. Environmental Res. (2018) 168:178-92. doi: 10.1016/j.envres.2018.09.038

102. Duarte JH, Di Meglio P, Hirota K, Ahlfors H, Stockinger B. Differential influences of the aryl hydrocarbon receptor on Th17 mediated responses in vitro and in vivo. PLoS ONE (2013) 8:e79819. doi: 10.1371/journal.pone.0079819

103. Kerkvliet NI, Steppan LB, Vorachek W, Oda S, Farrer D, Wong CP, et al. Activation of aryl hydrocarbon receptor by TCDD prevents diabetes in NOD mice and increases Foxp3 $+\mathrm{T}$ cells in pancreatic lymph nodes. Immunotherapy (2009) 1:539-47. doi: 10.2217/imt.09.24

104. Ishimaru N, Takagi A, Kohashi M, Yamada A, Arakaki R, Kanno J, et al. Neonatal exposure to low-dose 2,3,7,8-tetrachlorodibenzo-p-dioxin causes autoimmunity due to the disruption of T cell tolerance. J Immunol. (2009) 182:6576-86. doi: 10.4049/jimmunol.0802289

105. Boule LA, Burke CG, Fenton BM, Thevenet-Morrison K, Jusko TA, Lawrence BP. Developmental activation of the AHR increases effector CD4+ T cells and exacerbates symptoms in autoimmune disease-prone Gnaq+/- Mice. Toxicol Sci. (2015) 148:555-66. doi: 10.1093/toxsci/kfv203

106. Fu J, Nogueira SV, van Drongelen V, Coit P, Ling S, Rosloniec EF, et al. Shared epitope-aryl hydrocarbon receptor crosstalk underlies the mechanism of gene-environment interaction in autoimmune arthritis. Proc Natl Acad Sci USA. (2018) 115:4755-60. doi: 10.1073/pnas.1722124115 
107. Singh NP, Singh UP, Rouse M, Zhang J, Chatterjee S, Nagarkatti PS, et al. Dietary indoles suppress delayed-type hypersensitivity by inducing a switch from proinflammatory Th17 cells to anti-inflammatory regulatory T cells through regulation of microRNA. J Immunol. (2016) 196:1108-22. doi: 10.4049/jimmunol.1501727

108. Ehrlich AK, Pennington JM, Wang X, Rohlman D, Punj S, Lohr CV, et al. Activation of the Aryl hydrocarbon receptor by 10-Cl-BBQ prevents insulitis and effector $\mathrm{T}$ cell development independently of Foxp3+ regulatory T cells in nonobese diabetic mice. J Immunol. (2016) 196:264-73. doi: 10.4049/jimmunol.1501789

109. Tong B, Yuan X, Dou Y, Wu X, Chou G, Wang Z, et al. Norisoboldine, an isoquinoline alkaloid, acts as an aryl hydrocarbon receptor ligand to induce intestinal Treg cells and thereby attenuate arthritis. Int J Biochem Cell Biol. (2016) 75:63-73. doi: 10.1016/j.biocel.2016.03.014

110. Yuan X, Tong B, Dou Y, Wu X, Wei Z, Dai Y. Tetrandrine ameliorates collagen-induced arthritis in mice by restoring the balance between Th17 and Treg cells via the aryl hydrocarbon receptor. Biochem Pharmacol. (2016) 101:87-99. doi: 10.1016/j.bcp.2015.11.025

111. Tong B, Yuan X, Dou Y, Wu X, Wang Y, Xia Y, et al. Sinomenine induces the generation of intestinal Treg cells and attenuates arthritis via activation of aryl hydrocarbon receptor. Lab Invest. (2016) 96:1076-86. doi: 10.1038/labinvest.2016.86

112. Kaye J, Piryatinsky V, Birnberg T, Hingaly T, Raymond E, Kashi R, et al. Laquinimod arrests experimental autoimmune encephalomyelitis by activating the aryl hydrocarbon receptor. Proc Natl Acad Sci USA. (2016) 113:E6145-52. doi: 10.1073/pnas.1607843113

113. Quintana FJ, Murugaiyan G, Farez MF, Mitsdoerffer M, Tukpah AM, Burns EJ, et al. An endogenous aryl hydrocarbon receptor ligand acts on dendritic cells and T cells to suppress experimental autoimmune encephalomyelitis. Proc Natl Acad Sci USA. (2010) 107:20768-73. doi: 10.1073/pnas.1009201107

114. Rouse M, Singh NP, Nagarkatti PS, Nagarkatti M. Indoles mitigate the development of experimental autoimmune encephalomyelitis by induction of reciprocal differentiation of regulatory $\mathrm{T}$ cells and $\mathrm{Th17}$ cells. $\mathrm{Br} \mathrm{J}$ Pharmacol. (2013) 169:1305-21. doi: 10.1111/bph.12205

115. Nakahama T, Kimura A, Nguyen NT, Chinen I, Hanieh H, Nohara K, et al. Aryl hydrocarbon receptor deficiency in T cells suppresses the development of collagen-induced arthritis. Proc Natl Acad Sci USA. (2011) 108:14222-7. doi: 10.1073/pnas.1111786108

116. Talbot J, Peres RS, Pinto LG, Oliveira RDR, Lima KA, Donate PB, et al. Smoking-induced aggravation of experimental arthritis is dependent of aryl hydrocarbon receptor activation in Th17 cells. Arthritis Res Ther. (2018) 20:119. doi: 10.1186/s13075-018-1609-9

117. Ehrlich A, Pennington J, Greer R, Shulzhenko N, Kerkvliet N. Characterization of the microbiome in association with reduced diabetes incidence in AhR deficient NOD mice. J Immunol. (2016) 196:118.22.

118. Lahoti TS, John K, Hughes JM, Kusnadi A, Murray IA, Krishnegowda G, Amin et al. Aryl hydrocarbon receptor antagonism mitigates cytokine-mediated inflammatory signalling in primary human fibroblast-like synoviocytes. Ann Rheum Dis. (2013) 72:1708-16. doi: 10.1136/annrheumdis-2012-202639

119. Lahoti TS, Hughes JM, Kusnadi A, John K, Zhu B, Murray IA, et al. Aryl hydrocarbon receptor antagonism attenuates growth factor expression, proliferation, and migration in fibroblast-like synoviocytes from patients with rheumatoid arthritis. J Pharmacol Exp Ther. (2014) 348:236-45. doi: 10.1124/jpet.113.209726

120. Andrysik Z, Vondracek J, Marvanova S, Ciganek M, Neca J, Pencikova K, et al. Activation of the aryl hydrocarbon receptor is the major toxic mode of action of an organic extract of a reference urban dust particulate matter mixture: the role of polycyclic aromatic hydrocarbons. Mutat Res. (2011) 714:53-62. doi: 10.1016/j.mrfmmm.2011.06.011

121. Arrieta DE, Ontiveros CC, Li WW, Garcia JH, Denison MS, McDonald JD, et al. Aryl hydrocarbon receptor-mediated activity of particulate organic matter from the Paso del Norte airshed along the U.S.-Mexico border. Environ Health Perspect. (2003) 111:1299-305. doi: 10.1289/ehp.6058

122. den Hartigh LJ, Lame MW, Ham W, Kleeman MJ, Tablin F, Wilson DW. Endotoxin and polycyclic aromatic hydrocarbons in ambient fine particulate matter from Fresno, California initiate human monocyte inflammatory responses mediated by reactive oxygen species. Toxicol In Vitro (2010) 24:1993-2002. doi: 10.1016/j.tiv.2010.08.017

123. Jaguin M, Fardel O, Lecureur V. Exposure to diesel exhaust particle extracts (DEPe) impairs some polarization markers and functions of human macrophages through activation of AhR and Nrf2. PLoS ONE (2015) 10:e0116560 doi: 10.1371/journal.pone. 0116560

124. Gauggel-Lewandowski S, Heussner AH, Steinberg P, Pieterse B, van der Burg B, Dietrich DR. Bioavailability and potential carcinogenicity of polycyclic aromatic hydrocarbons from wood combustion particulate matter in vitro. Chem Biol Interact. (2013) 206:411-22. doi: 10.1016/j.cbi.2013.05.015

125. Libalova H, Krckova S, Uhlirova K, Milcova A, Schmuczerova J, Ciganek $\mathrm{M}$, et al. Genotoxicity but not the AhR-mediated activity of PAHs is inhibited by other components of complex mixtures of ambient air pollutants. Toxicol Lett. (2014) 225:350-7. doi: 10.1016/j.toxlet.2014. 01.028

126. Vondracek J, Pencikova K, Neca J, Ciganek M, Grycova A, Dvorak Z, et al. Assessment of the aryl hydrocarbon receptor-mediated activities of polycyclic aromatic hydrocarbons in a human cell-based reporter gene assay. Environ Pollut. (2017) 220(Pt A), 307-16. doi: 10.1016/j.envpol.2016.09.064

127. Misaki K, Suzuki M, Nakamura M, Handa H, Iida M, Kato T, et al. Aryl hydrocarbon receptor and estrogen receptor ligand activity of organic extracts from road dust and diesel exhaust particulates. Arch Environ Contam Toxicol. (2008) 55:199-209. doi: 10.1007/s00244-007-9110-5

128. Palkova L, Vondracek J, Trilecova L, Ciganek M, Pencikova K, Neca J, et al. The aryl hydrocarbon receptor-mediated and genotoxic effects of fractionated extract of standard reference diesel exhaust particle material in pulmonary, liver and prostate cells. Toxicol In Vitro (2015) 29:438-48. doi: 10.1016/j.tiv.2014.12.002

129. Burbach KM, Poland A, Bradfield CA. Cloning of the Ah-receptor cDNA reveals a distinctive ligand-activated transcription factor. Proc Natl Acad Sci USA (1992) 89:8185-9. doi: 10.1073/pnas.89.17.8185

130. Ema M, Sogawa K, Watanabe N, Chujoh Y, Matsushita N, Gotoh O, et al. cDNA cloning and structure of mouse putative Ah receptor. Biochem Biophys Res Commun. (1992) 184:246-53. doi: 10.1016/0006-291X(92)91185-S

131. Perdew GH. Association of the Ah receptor with the $90-\mathrm{kDa}$ heat shock protein. J Biol Chem. (1988) 263:13802-5.

132. Denis M, Cuthill S, Wikstrom AC, Poellinger L, Gustafsson JA. Association of the dioxin receptor with the Mr 90,000 heat shock protein: a structural kinship with the glucocorticoid receptor. Biochem Biophys Res Commun. (1988) 155:801-7. doi: 10.1016/S0006-291X(88)80566-7

133. Carver LA, Bradfield CA. Ligand-dependent interaction of the Aryl hydrocarbon receptor with a novel immunophilin homolog in vivo. (1997) J Biol Chem. 272:11452-6. doi: 10.1074/jbc.272.17.11452

134. Ma Q, Whitlock JP Jr. A novel cytoplasmic protein that interacts with the Ah receptor, contains tetratricopeptide repeat motifs, and augments the transcriptional response to 2,3,7,8-tetrachlorodibenzo-p-dioxin. J Biol Chem. (1997) 272:8878-84. doi: 10.1074/jbc.272.14.8878

135. Kazlauskas A, Poellinger L, Pongratz I. Evidence that the co-chaperone p 23 regulates ligand responsiveness of the dioxin (Aryl hydrocarbon) receptor. $J$ Biol Chem. (1999) 274:13519-24. doi: 10.1074/jbc.274.19.13519

136. Pongratz I, Mason GG, Poellinger L. Dual roles of the $90-\mathrm{kDa}$ heat shock protein hsp90 in modulating functional activities of the dioxin receptor. Evidence that the dioxin receptor functionally belongs to a subclass of nuclear receptors which require hsp90 both for ligand binding activity and repression of intrinsic DNA binding activity. J Biol Chem. (1992) 267:13728-34.

137. Soshilov A, Denison MS. Ligand displaces heat shock protein 90 from overlapping binding sites within the aryl hydrocarbon receptor ligand-binding domain (2011) J Biol Chem. 286:35275-82. doi: $10.1074 /$ jbc.M111.246439

138. Henry EC, Gasiewicz TA. Transformation of the aryl hydrocarbon receptor to a DNA-binding form is accompanied by release of the $90 \mathrm{kDa}$ heat-shock protein and increased affinity for 2,3,7,8-tetrachlorodibenzo-p-dioxin (1993) 294(Pt 1):95-101.

139. Bunger MK, Moran SM, Glover E, Thomae TL, Lahvis GP, Lin BC, et al. Resistance to 2,3,7,8-tetrachlorodibenzo-p-dioxin toxicity and abnormal liver development in mice carrying a mutation in the nuclear localization 
sequence of the aryl hydrocarbon receptor. J Biol Chem. (2003) 278:1776774. doi: $10.1074 /$ jbc.M209594200

140. Wilhelmsson A, Cuthill S, Denis M, Wikstrom AC, Gustafsson JA, Poellinger L. The specific DNA binding activity of the dioxin receptor is modulated by the $90 \mathrm{kd}$ heat shock protein. EMBO J (1990) 9:69-76. doi: 10.1002/j.1460-2075.1990.tb08081.x

141. Ikuta $T$, Eguchi $H$, Tachibana $T$, Yoneda $Y$, Kawajiri $K$. Nuclear localization and export signals of the human aryl hydrocarbon receptor. $J$ Biol Chem. (1998) 273:2895-904. doi: 10.1074/jbc.273.5.2895

142. Reyes H, Reisz-Porszasz S, Hankinson O. Identification of the Ah receptor nuclear translocator protein (Arnt) as a component of the DNA binding form of the Ah receptor. Science (1992) 256:1193-5. doi: $10.1126 /$ science. 256.5060 .1193

143. Dolwick KM, Swanson HI, Bradfield CA. In vitro analysis of Ah receptor domains involved in ligand-activated DNA recognition. Proc Natl Acad Sci USA. (1993) 90:8566-70. doi: 10.1073/pnas.90.18.8566

144. Lusska A, Shen E, Whitlock JP Jr. Protein-DNA interactions at a dioxinresponsive enhancer. Analysis of six bona fide DNA-binding sites for the liganded Ah receptor. J Biol Chem. (1993) 268:6575-80.

145. Shen ES, Whitlock JP Jr. Protein-DNA interactions at a dioxin-responsive enhancer. Mutational analysis of the DNA-binding site for the liganded Ah receptor. J Biol Chem. (1992) 267:6815-9.

146. Hankinson $\mathrm{O}$. Role of coactivators in transcriptional activation by the aryl hydrocarbon receptor. Arch Biochem Biophys. (2005) 433:379-86. doi: 10.1016/j.abb.2004.09.031

147. Tukey RH, Hannah RR, Negishi M, Nebert DW, Eisen HJ. The Ah locus: correlation of intranuclear appearance of inducer-receptor complex with induction of cytochrome P1-450 mRNA. Cell (1982) 31:275-84. doi: 10.1016/0092-8674(82)90427-5

148. Mezrich JD, Nguyen LP, Kennedy G, Nukaya M, Fechner JH, Zhang X, et al. SU5416, a VEGF receptor inhibitor and ligand of the AHR, represents a new alternative for immunomodulation. PLoS ONE (2012) 7:e44547. doi: 10.1371/journal.pone. 0044547

149. Davarinos NA, Pollenz RS. Aryl hydrocarbon receptor imported into the nucleus following ligand binding is rapidly degraded via the cytosplasmic proteasome following nuclear export. J Biol Chem. (1999) 274:28708-15. doi: $10.1074 /$ jbc. 274.40 .28708

150. Pollenz RS. The aryl-hydrocarbon receptor, but not the aryl-hydrocarbon receptor nuclear translocator protein, is rapidly depleted in hepatic and nonhepatic culture cells exposed to 2,3,7,8-tetrachlorodibenzo-p-dioxin. Mol Pharmacol. (1996) 49:391-8.

151. Roberts BJ, Whitelaw ML. Degradation of the basic helix-loop-helix/PerARNT-Sim homology domain dioxin receptor via the ubiquitin/proteasome pathway. J Biol Chem. (1999) 274:36351-6. doi: 10.1074/jbc.274.51.36351

152. Mimura J, Ema M, Sogawa K, Fujii-Kuriyama Y. Identification of a novel mechanism of regulation of Ah (dioxin) receptor function. Genes Dev. (1999) 13:20-5. doi: 10.1101/gad.13.1.20

153. Funatake CJ, Marshall NB, Steppan LB, Mourich DV, Kerkvliet NI. Cutting Edge. Activation of the aryl hydrocarbon receptor by 2,3,7,8Tetrachlorodibenzo-p-dioxin generates a population of CD4+CD25+ cells with characteristics of regulatory T Cells J Immunol. (2005) 175:4184-8. doi: 10.4049/jimmunol.175.7.4184

154. Dant TA, Lin KL, Bruce DW, Montgomery SA, Kolupaev OV, Bommiasamy $\mathrm{H}$, et al. T-cell expression of AhR inhibits the maintenance of pTreg cells in the gastrointestinal tract in acute GVHD. Blood (2017) 130:348-59. doi: 10.1182/blood-2016-08-734244

155. Veiga-Parga T, Suryawanshi A, Rouse BT. Controlling viral immunoinflammatory lesions by modulating aryl hydrocarbon receptor signaling. PLoS Pathog. (2011) 7:e1002427. doi: 10.1371/journal.ppat.1002427

156. Mezrich JD, Fechner JH, Zhang X, Johnson BP, Burlingham WJ, Bradfield CA. An interaction between kynurenine and the aryl hydrocarbon receptor can generate regulatory T cells. J Immunol. (2010) 185:3190-8. doi: 10.4049/jimmunol.0903670

157. Abron JD, Singh NP, Mishra MK, Price RL, Nagarkatti M, Nagarkatti PS, et al. An endogenous aryl hydrocarbon receptor (AhR) ligand, ITE induces regulatory $\mathrm{T}$ cells (Tregs) and ameliorates experimental colitis. Am J Physiol Gastrointest Liver Physiol. (2018) 315:G220-30. doi: 10.1152/ajpgi.00413.2017
158. Julliard W, De Wolfe TJ, Fechner JH, Safdar N, Agni R, Mezrich JD. Amelioration of clostridium difficile infection in mice by dietary supplementation with Indole-3-carbinol. Ann Surg. (2017) 265:1183-91. doi: $10.1097 /$ SLA.0000000000001830

159. Julliard W, Fechner JH, Owens L, O'Driscoll CA, Zhou L, Sullivan JA, et al. Modeling the effect of the aryl hydrocarbon receptor on transplant immunity. Transplant Direct (2017) 3:e157. doi: 10.1097/TXD.0000000000000666

160. Liu X, Hu H, Fan H, Zuo D, Shou Z, Liao Y, et al. The role of STAT3 and AhR in the differentiation of $\mathrm{CD} 4+\mathrm{T}$ cells into Th17 and Treg cells. Medicine (2017) 96:e6615. doi: 10.1097/MD.0000000000006615

161. Ehrlich AK, Pennington JM, Bisson WH, Kolluri SK, Kerkvliet NI. TCDD, FICZ, and other high affinity AhR ligands dose-dependently determine the fate of CD4+ T cell differentiation. Toxicol Sci. (2018) 161:310-20. doi: $10.1093 /$ toxsci/kfx215

162. Pot C, Apetoh L, Awasthi A, Kuchroo VK. Induction of regulatory Tr1 cells and inhibition of T(H)17 cells by IL-27. Semin Immunol. (2011) 23:438-45. doi: 10.1016/j.smim.2011.08.003

163. Gandhi R, Kumar D, Burns EJ, Nadeau M, Dake B, Laroni A, et al. Activation of the aryl hydrocarbon receptor induces human type 1 regulatory $\mathrm{T}$ celllike and Foxp3(+) regulatory T cells. Nat Immunol. (2010) 11:846-53. doi: 10.1038/ni.1915

164. Mohinta S, Kannan AK, Gowda K, Amin SG, Perdew GH, August A. Differential regulation of Th17 and T regulatory cell differentiation by aryl hydrocarbon receptor dependent xenobiotic response element dependent and independent pathways. Toxicol Sci. (2015) 145:233-43. doi: $10.1093 /$ toxsci/kfv046

165. Pearson JA, Wong FS, Wen L. The importance of the Non Obese Diabetic (NOD) mouse model in autoimmune diabetes. J Autoimmun. (2016) 66:7688. doi: 10.1016/j.jaut.2015.08.019

166. Delovitch TL, Singh B. The nonobese diabetic mouse as a model of autoimmune diabetes: immune dysregulation gets the NOD. Immunity (1997) 7:727-38. doi: 10.1016/S1074-7613(00)80392-1

167. Bellemore SM, Nikoopour E, Schwartz JA, Krougly O, Lee-Chan E, Singh B. Preventative role of interleukin-17 producing regulatory $\mathrm{T}$ helper type 17 (Treg 17) cells in type 1 diabetes in non-obese diabetic mice. Clin Exp Immunol. (2015) 182:261-9. doi: 10.1111/cei.12691

168. Cheng L, Qian L, Tan Y, Wang GS, Li XM, Li XP, et al. Unbalanced expression of aryl hydrocarbon receptor in peripheral blood CCR6 $(+) \mathrm{CD} 4(+)$ and CD4(+)CD25(+)T cells of rheumatoid arthritis. Rev Bras Reumatol. (2017) 57:190-6. doi: 10.1016/j.rbr.2016.04.003

169. Pietrosimone KM, Jin M, Poston B, Liu P. Collagen-induced arthritis: a model for murine autoimmune arthritis. Bio Protoc. (2015) 5:e1626. doi: 10.21769/BioProtoc. 1626

170. Tong B, Yu J, Wang T, Dou Y, Wu X, Kong L, et al. Sinomenine suppresses collagen-induced arthritis by reciprocal modulation of regulatory $\mathrm{T}$ cells and Th17 cells in gut-associated lymphoid tissues. Mol Immunol. (2015) 65:94-103. doi: 10.1016/j.molimm.2015.01.014

171. Gold R, Linington C, Lassmann H. Understanding pathogenesis and therapy of multiple sclerosis via animal models: 70 years of merits and culprits in experimental autoimmune encephalomyelitis research. Brain (2006) 129(Pt 8):1953-71. doi: 10.1093/brain/awl075

172. Cua DJ, Sherlock J, Chen Y, Murphy CA, Joyce B, Seymour B, et al. Interleukin-23 rather than interleukin-12 is the critical cytokine for autoimmune inflammation of the brain. Nature (2003) 421:744-8. doi: 10.1038/nature01355

173. Park H, Li Z, Yang XO, Chang SH, Nurieva RY, Wang H, et al. A distinct lineage of $\mathrm{CD} 4 \mathrm{~T}$ cells regulates tissue inflammation by producing interleukin 17. Nature Immunol. (2005) 6:1133. doi: 10.1038/ ni1261

174. Harrington LE, Hatton RD, Mangan PR, Turner H, Murphy TL, Murphy $\mathrm{KM}$, et al. Interleukin 17-producing CD4+ effector T cells develop via a lineage distinct from the Thelper type 1 and 2 lineages. Nat Immunol. (2005) 6:1123-32. doi: 10.1038/ni1254

175. Rothhammer V, Borucki DM, Garcia Sanchez MI, Mazzola MA, Hemond CC, Regev $\mathrm{K}$, et al. Dynamic regulation of serum aryl hydrocarbon receptor agonists in MS. Neurol Neuroimmunol Neuroinflamm. (2017) 4:e359. doi: 10.1212/NXI.0000000000000359 
176. Apetoh L, Quintana FJ, Pot C, Joller N, Xiao S, Kumar D, et al. The aryl hydrocarbon receptor interacts with c-Maf to promote the differentiation of type 1 regulatory T cells induced by IL-27. Nat Immunol. (2010) 11:854-61. doi: $10.1038 /$ ni. 1912

177. Rekik R, Smiti Khanfir M, Larbi T, Zamali I, Beldi-Ferchiou A, Kammoun $\mathrm{O}$, et al. Impaired TGF-beta signaling in patients with active systemic lupus erythematosus is associated with an overexpression of IL-22. Cytokine (2018) 108:182-9. doi: 10.1016/j.cyto.2018.04.011

178. Dorgham K, Amoura Z, Parizot C, Arnaud L, Frances C, Pionneau C, et al. Ultraviolet light converts propranolol, a nonselective betablocker and potential lupus-inducing drug, into a proinflammatory AhR ligand. Eur J Immunol. (2015) 45:3174-87. doi: 10.1002/eji.2014 45144

179. Shinde R, Hezaveh K, Halaby MJ, Kloetgen A, Chakravarthy A, Medina TdS, et al. Apoptotic cell-induced AhR activity is required for immunological tolerance and suppression of systemic lupus erythematosus in mice and humans. Nat Immunol. (2018) 19:571. doi: 10.1038/s41590-0180107-1

180. Zhang P, Wang R, Li Z, Wang Y, Gao C, Lv X, et al. The risk of smoking on multiple sclerosis: a meta-analysis based on 20,626 cases from case-control and cohort studies. PeerJ (2016) 4:e1797. doi: 10.7717/peerj.1797

181. Poorolajal J, Bahrami M, Karami M, Hooshmand E. Effect of smoking on multiple sclerosis: a meta-analysis. J Public Health (2018) 39:312-20. doi: $10.1093 /$ pubmed/fdw030
182. Costenbader KH, Kim DJ, Peerzada J, Lockman S, Nobles-Knight D, Petri $\mathrm{M}$, et al. Cigarette smoking and the risk of systemic lupus erythematosus: a meta-analysis. Arthritis Rheum. (2004) 50:849-57. doi: 10.1002/art.20049

183. Chang K, Yang SM, Kim SH, Han KH, Park SJ, Shin JI. Smoking and rheumatoid arthritis. Int J Mol Sci. (2014) 15:22279-95. doi: 10.3390/ijms151222279

184. Perricone C, Versini M, Ben-Ami D, Gertel S, Watad A, Segel MJ, et al. Smoke and autoimmunity. The fire behind the disease. Autoimmun Rev. (2016) 15:354-74. doi: 10.1016/j.autrev.2016.01.001

185. Harel-Meir M, Sherer Y, Shoenfeld Y. Tobacco smoking and autoimmune rheumatic diseases. Nat Clin Pract Rheumatol. (2007) 3:707-15. doi: $10.1038 /$ ncprheum 0655

Conflict of Interest Statement: The authors declare that the research was conducted in the absence of any commercial or financial relationships that could be construed as a potential conflict of interest.

Copyright () 2018 O'Driscoll and Mezrich. This is an open-access article distributed under the terms of the Creative Commons Attribution License (CC BY). The use, distribution or reproduction in other forums is permitted, provided the original author(s) and the copyright owner(s) are credited and that the original publication in this journal is cited, in accordance with accepted academic practice. No use, distribution or reproduction is permitted which does not comply with these terms. 